\title{
Ru passivated and Ru doped epsilon-TaN surfaces as a combined barrier and liner material for copper interconnects: a first principles study
}

Natarajan, S. K., Nies, C-L., \& Nolan, M. (2019). Ru passivated and Ru doped epsilon-TaN surfaces as a combined barrier and liner material for copper interconnects: a first principles study. Journal of Materials Chemistry C, 7(26), 7959-7973. https://doi.org/10.1039/c8tc06118a

Link to publication record in Ulster University Research Portal

\section{Published in:}

Journal of Materials Chemistry C

\section{Publication Status:}

Published (in print/issue): 21/05/2019

DOI:

10.1039/c8tc06118a

\section{Document Version}

Author Accepted version

\section{General rights}

Copyright for the publications made accessible via Ulster University's Research Portal is retained by the author(s) and / or other copyright owners and it is a condition of accessing these publications that users recognise and abide by the legal requirements associated with these rights.

\section{Take down policy}

The Research Portal is Ulster University's institutional repository that provides access to Ulster's research outputs. Every effort has been made to ensure that content in the Research Portal does not infringe any person's rights, or applicable UK laws. If you discover content in the Research Portal that you believe breaches copyright or violates any law, please contact pure-support@ulster.ac.uk. 
Cite this: DOI: $10.1039 /$ xxxxxxxxxx

Accepted Date

DOI: $10.1039 / x x x x x x x x x x$

www.rsc.org/journalname

\section{Ru Passivated and Ru Doped $\varepsilon$-TaN surfaces as Com- bined Barrier and Liner Material for Copper Intercon- nects: A First Principles Study}

\author{
Suresh Kondati Natarajan*, Cara-Lena Nies* and Michael Nolan
}

\section{Introduction}

Within the semiconductor industry, scaling of interconnects is the most significant limiting factor in the scaling of CMOS transitors. ${ }^{112}$ In 1997, the replacement of $\mathrm{Al}$ with $\mathrm{Cu}$ for interconnects overcame some of the issues identified in the International Technology Roadmap for Semiconductors (ITRS) for several technological nodes. However this change has introduced other issues. $3 \sqrt[34]{3}$

University College Cork, Tyndall National Institute, Lee Maltings, Dyke Parade, Cork, T12 R5CP, Ireland. Tel: +353 21234 6983; E-mail: michael.nolan@tyndall.ie

*Authors contributed equally to the manuscript. Author SKN did calculations on the bare TaN surfaces, bare Ru surface and Ru passivated surfaces; Author CLN did calculations on the Ru doped TaN surfaces. † Electronic Supplementary Information (ESI) available. See DOI: 10.1039/b000000x/
These include electromigration, which has detrimental effects on device lifetime, as well as the diffusion of $\mathrm{Cu}$ into the dielectric.4 While these issues were also overcome with the use of barrier materials such as Ta and TaN, they are resurfacing as downscaling of devices is set to continue beyond the $5 \mathrm{~nm}$ node. ${ }^{4 / 6}$ Other problems such as increased $\mathrm{Cu}$ resistivity and finding materials that promote $\mathrm{Cu}$ electroplating have also been encountered. .47

The original diffusion barriers for $\mathrm{Cu}$ interconnects were Ta and $\mathrm{Si}_{3} \mathrm{~N}_{4}$. ${ }^{6}$ Since then, a large number of materials have been studied in order to improve device performance and to drive scaling. ${ }^{819}$ Kaloyeros and Eisenbraun ${ }^{10}$ identified refractory transition metals, as well as their binary and ternary systems, as the most promising candidates for $\mathrm{Cu}$ diffusion barriers, due to their very high melting temperatures. For compounds with melting tempera- 
tures this high, fast diffusion mechanisms such as grain boundary diffusion become negligible at the operating temperatures of the devices. Grain boundary diffusion has been identified frequently in the literature as the main failure mechanism for $\mathrm{Cu}$ diffusion barriers. ${ }^{9111}$ Kaloyeros and Eisenbraun $\frac{10}{10}$ also classified possible diffusion barrier materials into seven groups. The first and second groups comprise pure refractory metals and metal alloys, such as $\mathrm{Ta}{ }^{[12}$, Mo and $\mathrm{Os},{ }^{13]} \mathrm{Ru}^{[14[15]}$ and Ru-Ta alloy. ${ }^{[16}$ Groups three and four include polycrystalline or amorphous refractory metal nitrides, oxides, carbides, borides and silicates, such as $\mathrm{TaN}_{\mathrm{X}}, 17118$ TiN, 19 and $\mathrm{WN}_{\mathrm{X}} \cdot \frac{11}{11}$ Some of the more complex materials are included in groups five, six and seven. These are polycrystalline or amorphous silicon nitrides and carbides; amorphous ternary barriers such as TaSiN, WBN and TiSiN; and carbon based compounds such as diamond like carbon coatings. Arguably, 2D materials such as graphene could be added as an eighth group. Graphene has been quite well studied by the research community ever since it was first obtained experimentally. ${ }^{20}$ Moreover, there is a growing interest in materials such as $\mathrm{MoS}_{2}$ and graphene as alternative diffusion barrier materials. 2122

At present, the semiconductor industry uses a stack of $\mathrm{TaN} / \mathrm{Ta} / \mathrm{Cu}$. This stack acts as a diffusion barrier to prevent $\mathrm{Cu}$ diffusion into the dielectric as well as a $\mathrm{Cu}$ adhesion promoter, also referred to as a liner. ${ }^{23}$ However, as technology nodes continue to be scaled down to allow greater performance and lower power consumption, a number of issues begin to arise. These include electromigration as well as the increase in $\mathrm{Cu}$ resistance. Further, the tri-layer barrier stack becomes difficult to grow via the traditional physical vapour depostion (PVD) methods and while atomic layer deposition (ALD) ${ }^{24}$ and atomic layer etch (ALE) 25 have shown promise for film growth at the $<5 \mathrm{~nm}$ scale, the three layers are still difficult to grow in high aspect ratio vias. ${ }^{26}$ This gives rise to the need for alternative, ultrathin barrier materials or a single material that combines all the characteristics of the trilayer stack. $.46[23]$ Many of the refractory transition metal binaries, such as TaN and WN, are poly-crystalline which cause device failure through grain boundary diffusion. ${ }^{[8}$ It is therefore suggested that amorphous materials would provide better protection against $\mathrm{Cu}$ diffusion. By incorporating $\mathrm{Si}$ or $\mathrm{O}$ into refractory metal nitrides, an amorphous ternary material can be formed, which is suggested to be a more favourable barrier than its binary counterpart. ${ }^{27}$ There is however an issue that these amorphous ternary materials have increased resistivity $[89$

To our knowledge, the barrier materials mentioned above were mostly studied experimentally to determine the diffusion mechanism and the conditions at which the materials could operate. There have been fewer theoretical studies using density functional theory (DFT) on the use of refractory metals as copper diffusion barriers or their use as liner layers, focusing on a variety of different metals. ${ }^{2829}$ Pure TaN is an excellent barrier for copper diffusion, however it is not well suited for copper electroplating.7 Nevertheless, when combined with a suitable liner material such as $\mathrm{Ru}$, it has great potential to overcome some of the challenges mentioned above. 28 The phase diagram of TaN determined by Frisk (see section S1 of ESI $\dagger$ ) gives an overview of the different solid phase structures of TaN. ${ }^{30}$ The $\delta$ phase of TaN (fcc lattice) has been routinely employed in a number of studies in the literature. $\frac{1828}{128}$ However, the stoichiometric compound $\varepsilon$-TaN with $\mathrm{Fe}_{2} \mathrm{P}$ crystal structure ${ }^{31}$ has the most favourable formation energy. To the best of our knowledge, we found that this hexagonal phase has not been studied in detail computationally when compared to other phases of TaN. The $\left(\begin{array}{lll}0 & 0 & 1\end{array}\right)$ surface of $\varepsilon$-TaN has been studied previously by Lu and coworkers, $\frac{18}{18}$ where they investigated the interface between $\mathrm{Cu}\left(\begin{array}{lll}1 & 1 & 1\end{array}\right)$ and the TaN($\left(\begin{array}{lll}0 & 0 & 1\end{array}\right)$ surfaces. However, their study mainly focused on the surfaces of bcc and fcc TaN and they also did not address copper adatom adsorption and mobility at these surfaces. Cheng and co-workers ${ }^{28}$ studied the adhesion and mobility of monolayer/bilayer of $\mathrm{Cu}$ on N-terminated $\delta$-TaN(l $\left.\begin{array}{lll}1 & 1 & 1\end{array}\right)$ and $\operatorname{Ru}\left(\begin{array}{lll}0 & 0 & 1\end{array}\right)$ surfaces as well as monolayers of Cu on Ru passivated N-terminated $\delta$-TaN(llllll 111$)$ surface and predicted Ru as an ideal material for the glue layer that connects the barrier material with the copper wire. However they did not explicitly compute the activation energies for on-surface diffusion, sub-surface diffusion and agglomeration of $\mathrm{Ru} / \mathrm{Cu}$ adatoms on TaN surface which are important to understand the $\mathrm{Cu} / \mathrm{Ru}$ nucleation on the TaN surfaces. Therefore, in this paper we examine in detail the low index surfaces of $\varepsilon$-TaN and study the adsorption and diffusion of 1 and $2 \mathrm{Cu} / \mathrm{Ru}$ atoms in order to shed light on the mechanism of $\mathrm{Cu}$ adsorption, migration and nucleation to better understand $\mathrm{Cu}$ growth on barrier and liner films. We want to note that DFT studies of adsorption of metal atoms on oxides has a long history and is of high interest these days in e.g. single metal atom catalysts. $32 \sqrt{42}$ We study Ru passivated and Ru doped $\varepsilon$-TaN surfaces as they combine the advantages of decreased grain boundary diffusion of ternary materials, the excellent barrier characteristics of TaN and the good liner characteristics of Ru. Ru doped TaN has the potential to be a single barrier+liner material. The main aim of this paper is to find if either or both of these hybrid surfaces could perform effectively as the combined barrier+liner material that would break through the bottleneck in the scaling of copper interconnect technology.

\section{Methods and Computational Details}

All bulk and surface calculations are performed within DFT using the Vienna Ab initio Simulation Package (VASP) version 5.3.43 The valence electrons are described explicitly by expanding their wave function in a plane wave basis set with an energy cutoff of $400 \mathrm{eV}$ whereas the core electrons are treated by projector augmented wave (PAW) potentials. ${ }^{44 / 45}$ The valence electronic configurations of the $\mathrm{Ta}, \mathrm{N}, \mathrm{Ru}$ and $\mathrm{Cu}$ atoms used in these calculations are $6 s^{2} 5 d^{3}, 2 s^{2} 2 p^{3}, 4 d^{7} 5 s^{1}$ and $3 d^{10} 4 s^{1}$, respectively. The DFT calculations are based on spin polarized generalized gradient approximation (GGA) using Perdew-Burke-Ernzerhof (PBE) exchangecorrelation functional. 46 The activation energies reported in this paper are computed using climbing image nudged elastic band (CI-NEB) method with 5 images including the starting and ending geometries (3 images only for very short hops). ${ }^{47 / 48}$ The forces acting on the unconstrained atoms in the geometry relaxation calculations as well as the NEB forces in the activation energy computation are converged to $0.02 \mathrm{eV} / \AA$.

The bulk structure of $\varepsilon$-TaN with $\mathrm{Fe}_{2} \mathrm{P}$ crystal structure is chosen from the Materials Project database ${ }^{49}$ and the geometry is 
a) Bulk $\varepsilon-\mathrm{TaN}$

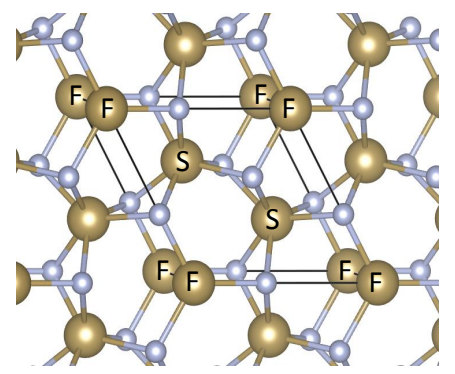

b) DOS of Bulk $\varepsilon-\mathrm{TaN}$

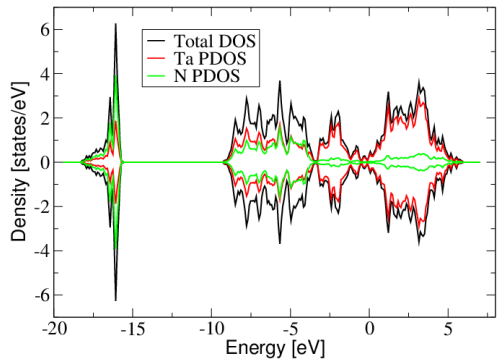

c) $\left(\begin{array}{lll}1 & 1 & 0\end{array}\right)$
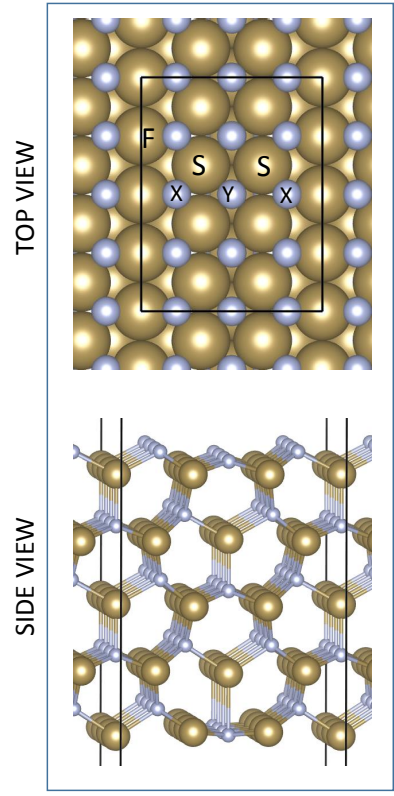

d) (1 111 )

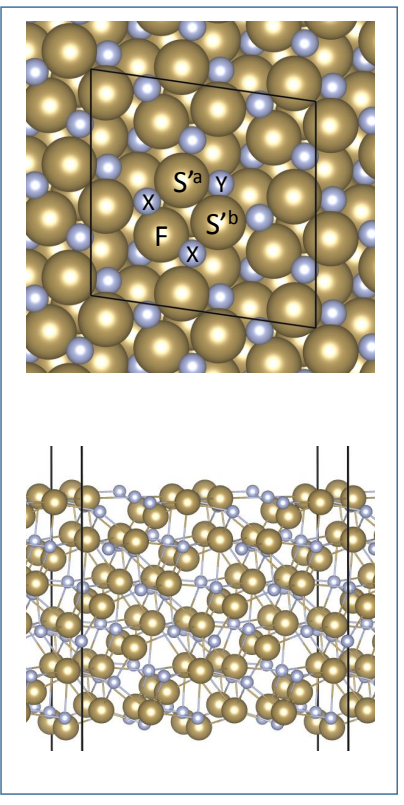

e) $\left(\begin{array}{lll}1 & 0 & 0\end{array}\right)$

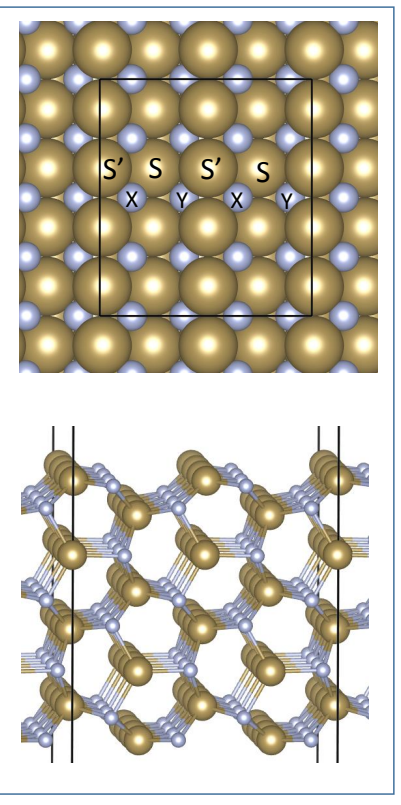

Fig. 1 Panel a) shows the bulk geometry of $\varepsilon$-TaN and panel b) shows the total (black line) and partial density of states (Ta in red and $\mathrm{N}$ in green) of $\varepsilon$-TaN where $0 \mathrm{eV}$ in x-axis marks the fermi level. The top and side views of (1 110$),\left(\begin{array}{lll}1 & 1 & 1\end{array}\right)$ and $\left(\begin{array}{lll}1 & 0 & 0\end{array}\right)$ surfaces of $\varepsilon$-TaN are given in panels $\mathrm{c}$ ), d) and

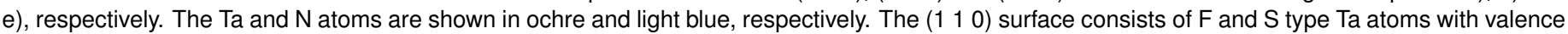
charges $(Q)$ of 3.6 and 3.0, respectively and $N$ atoms with $Q=6.3(X)$ and $Q=6.4(Y)$. Valence charges are computed with respect to total charge density using the Bader code from Henkelman's group. 50151 On the $\left(\begin{array}{lll}1 & 1 & 1\end{array}\right)$ surface, we have the $S$ type Ta atoms coordinated by $4 \mathrm{~N}$ atoms only (indicated as $\mathrm{S}^{\prime}$ ) with $\mathrm{Q}=3.5\left(\mathrm{~S}^{\prime a}\right)$ and $\mathrm{Q}=3.6\left(\mathrm{~S}^{\prime b}\right)$, $\mathrm{F}$ type Ta atoms with $\mathrm{Q}=3.7$ and $\mathrm{N}$ atoms with $\mathrm{Q}=6.5(\mathrm{X})$ or $\mathrm{Q}=6.4(\mathrm{Y})$. On the $\left(\begin{array}{lll}1 & 0 & 0\end{array}\right)$ surface, we have both $\mathrm{S}$ and S' type Ta atoms with $Q=3.2$ and $Q=3.7$, respectively and $N$ atoms with $Q=6.5(X)$ or $Q=6.4(Y)$.

Table 1 Details of the computation models of the low index surfaces of $\varepsilon$-TaN.

\begin{tabular}{|c|c|c|c|c|c|c|c|c|}
\hline Surface & Supercell & K-points & Surf. Area $\left[\mathrm{nm}^{2}\right]$ & Layers & TaN/layer & Slab Thickness $[\AA]$ & No. Atoms & $E_{\text {Surf }}\left[\mathrm{J} / \mathrm{m}^{2}\right]$ \\
\hline$\left(\begin{array}{lll}1 & 1 & 0\end{array}\right)$ & $(1 \times 4)$ & $3 \times 2 \times 1$ & 1.06 & 5 & 12 & 11.8 & 120 & 2.6 \\
\hline$\left(\begin{array}{lll}1 & 1 & 1\end{array}\right)$ & $(2 \times 2)$ & $3 \times 3 \times 1$ & 1.42 & 6 & 12 & 10.5 & 144 & 2.7 \\
\hline$\left(\begin{array}{lll}1 & 0 & 0\end{array}\right)$ & $(1 \times 4)$ & $2 \times 2 \times 1$ & 1.22 & 8 & 8 & 10.2 & 128 & 2.7 \\
\hline
\end{tabular}

optimized by simultaneously relaxing the ionic positions, cell volume and cell shape at a higher plane wave energy cutoff of 550 $\mathrm{eV}$ and a Monkhorst-Pack K-point mesh of $6 \times 6 \times 12$. From this calculation, we arrive at the following equilibrium lattice parameters: $\mathrm{a}=\mathrm{b}=5.23 \AA, \mathrm{c}=2.92 \AA, \alpha=\beta=90^{\circ}$ and $\gamma=120^{\circ}$. This agrees closely with the experimental results of $\mathrm{a}=\mathrm{b}=5.20 \AA$ and $\mathrm{C}=2.91 \AA .31$ The equilibrium geometry of bulk $\varepsilon$-TaN is shown in Figure 1 A.

Here, the Ta atoms marked with label ' $F$ ' are 3 fold coordinated by $\mathrm{N}$ atoms and the resulting coordination polyhedron of this $\mathrm{TaN}_{3}$ fragment is a planar triangle. Ta atoms marked with label ' $S$ ' are 6 fold coordinated by $\mathrm{N}$ atoms forming two trigonal pyramids connected by their vertices. All $\mathrm{N}$ atoms in this geometry are coordinated by 3 Ta atoms out of which two are ' $S$ ' type and one is ' $F$ ' type. From bader charge partitioning scheme $\mathrm{e}^{50 \mid 51}$ we find that the ' $F$ ' Ta atoms have a valence charge of 3.8 , the 'S' Ta atoms have a charge of 3.3 and the $\mathrm{N}$ atoms have a charge of 6.5. We have used the total charge density of the system including the core charges as the reference to compute the valence charges. Therefore the bonding between $\mathrm{Ta}$ and $\mathrm{N}$ atoms is of a combined ionic and covalent character. The electron affinity (EA) values of Ta and $\mathrm{N}$ atoms are $0.32 \mathrm{eV}$ and $-0.07 \mathrm{eV}$, respectively. Therefore it is not surprising to see that the Ta atoms were oxidized and $\mathrm{N}$ atoms were reduced. The total density of states (TDOS) of $\varepsilon$-TaN and the contributions from $\mathrm{Ta}$ and $\mathrm{N}$ atoms are shown in Figure $1 \mathrm{~b}$. It is clear that there is no band gap present and the valence and conduction bands are dominated by the electronic states of Ta. However, it is also observed that the DOS is significantly reduced in the region between the valence and conduction bands suggesting some resistance to electron flow which makes this material a semi-metal. The cohesive energy of $\varepsilon$-TaN is found to be $-1.20 \mathrm{eV} /$ atom with reference to bulk $\mathrm{Ta}^{52}$ and $\mathrm{N}_{2}$ molecule.

The three low index surfaces ((lll 111$\left.),\left(\begin{array}{lll}1 & 0 & 0\end{array}\right),\left(\begin{array}{lll}1 & 1 & 0\end{array}\right)\right)$ of $\varepsilon$ TaN are considered for this study as they have the lowest surface energies among the 7 possible low index surfaces (see section S2 of ESI $\dagger$ ). The surface models are generated with the help of the Atomic Simulation Environment (ASE) package ${ }^{53}$ and the properties of these surfaces are listed in Table $1,12 \AA$ of vacuum separating the slabs along the surface normal direction is included to avoid interactions between the two surfaces of the slab. Out 
of the three surfaces, the (1 110$)$ surface was found to have the

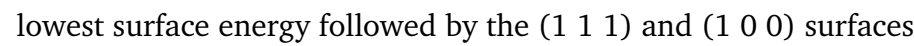
as shown in Table 1 . The top and side views of the equilibrium geometries of the above mentioned low-index surfaces along with the valence charges of the top layer atoms are given in Figure 1 -e. From the valence charges obtained from the Bader charge partitioning scheme, we find that the (lllll 110$),\left(\begin{array}{lll}1 & 0 & 0\end{array}\right)$ have surface Ta atoms that show different charges (Figure 1). The role of this in the adsorption of $\mathrm{Cu}$ and $\mathrm{Ru}$ is discussed in the results section. The electron affinity values of $\mathrm{Cu}$ and $\mathrm{Ru}$ are $1.24 \mathrm{eV}$ and $1.05 \mathrm{eV}$, respectively, which are much larger than that of Ta and N. Therefore we may expect the $\mathrm{Cu}$ and $\mathrm{Ru}$ adatoms to be oxidized, $\mathrm{Cu}$ more so than $\mathrm{Ru}$, when adsorbed on the TaN surfaces. For the adsorption calculations on the low index surfaces, the bottom two layers of the relaxed slab geometries are constrained in their positions.

Bulk Ru in the hexagonal close packed (HCP) lattice is also chosen for this study and the initial geometry is taken from the Materials Project database. $\sqrt[54]{ }$ The geometry is relaxed in a similar way to the TaN case with an increased energy cutoff of $550 \mathrm{eV}$ and a dense K-point mesh of $12 \times 12 \times 6$. From this the equilibrium lattice constants are found to be $\mathrm{a}=\mathrm{b}=2.71 \AA$, $\mathrm{c}=4.28 \AA, \alpha=\beta=90^{\circ}$ and $\gamma=120^{\circ}$, which compares well with the experimental results. 55 The cohesive energy per atom with reference to atomic Ru is computed to be $-6.81 \mathrm{eV}$, which also agrees with experiments. ${ }^{56}$ The geometry of bulk Ru showing the HCP arrangement is shown in Figure S3a of ESI. $\dagger$

The total DOS of Ru is plotted in Figure S3b of ESI $\dagger$ which shows its metallic nature. For the $\mathrm{Cu}$ adsorption calculations, a $10.5 \AA$ thick, 6 layered Ru(0 0 1) slab with a surface energy of $2.53 \mathrm{~J} / \mathrm{m}^{2}$, as shown in Figures S3c and S3d of ESI $\dagger$, is chosen and a Monkhorst-Pack K-point mesh of $3 \times 3 \times 1$ is used.

Surface energies reported in this paper are computed as follows:

$$
E_{\text {surf }}=\frac{1}{2 A}\left(E-\left(n E_{\mathrm{TaN}}\right)\right) .
$$

Where, $\mathrm{A}$ is the surface area of the supercell, $\mathrm{n}$ is the total number of TaN units in the supercell, $E_{\mathrm{TaN}}$ is the energy of a unit TaN in bulk and $E$ is the total energy of the surface. Adsorption/binding energies are computed using:

$$
E_{\text {bind }}=\left(E_{\text {total }}-\left(E_{\text {surface only }}+E_{\text {adsorbate only }}\right)\right) .
$$

Where, $E_{\text {total }}$ is the total energy of the interacting system (adsorbate atoms bound to the surface), $E_{\text {surface only }}$ and $E_{\text {adsorbate only }}$ are the total energies of the bare surface and isolated adsorbate atoms, respectively. Activation energy required by the system to hop from state A to state B is computed using:

$$
E_{\mathrm{A}-\mathrm{B}}=\left|\left(E_{\mathrm{A}}-\left(E_{\mathrm{TS}_{\mathrm{AB}}}\right)\right)\right| .
$$

Where, $E_{\mathrm{A}}$ is the energy of state $\mathrm{A}$ and $E_{\mathrm{TS}_{\mathrm{AB}}}$ is the energy of the transition state connecting states $\mathrm{A}$ and $\mathrm{B}$ that is computed using CI-NEB approach.

\section{Results}

In this section, we will first investigate the adsorption and diffusion of $\mathrm{Ru}$ and $\mathrm{Cu}$ adatoms at the most favourable low index surfaces

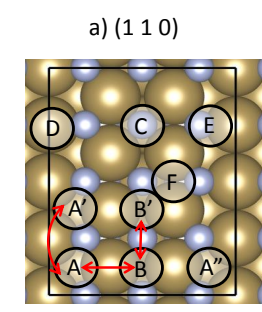

A

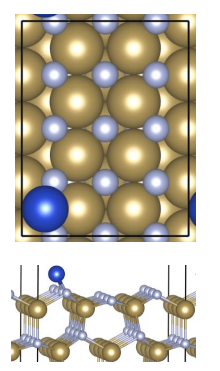

b) $\left(\begin{array}{lll}1 & 1 & 1\end{array}\right)$

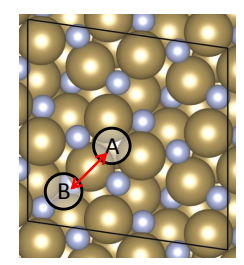

B
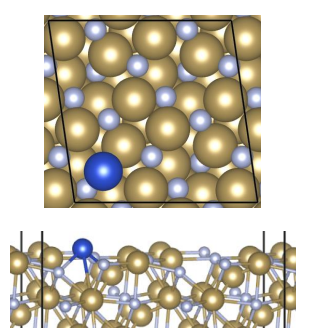

c) $\left(\begin{array}{lll}1 & 0 & 0\end{array}\right)$

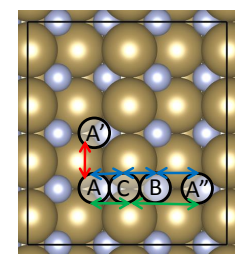

A

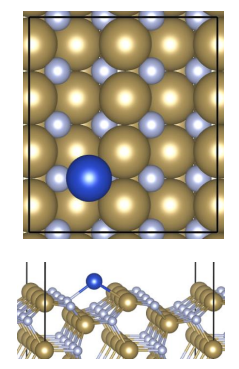

Fig. 2 The low index surfaces of TaN showing the unique binding sites, which are also the end points used for the Cl-NEB calculations to compute the activation energies for lateral diffusion of a single adatom. The red arrows indicate pathways for both $\mathrm{Ru}$ and $\mathrm{Cu}$ adatoms, green arrows are for $\mathrm{Cu}$ adatom and blue arrows are for $\mathrm{Ru}$ adatom. The $\mathrm{Ta}$ and $\mathrm{N}$ atoms are shown in ochre and light blue, respectively. The top and side views of the most favourable minimum geometry are also provided for each surface.

of TaN. Following this, similar calculations for $\mathrm{Cu}$ adatoms at a hexagonal $\mathrm{Ru}(0 \quad 0$ 1) slab will be reported. In the next subsection, Ru passivation on TaN and subsequent adsorption and diffusion of $\mathrm{Cu}$ atoms will be investigated. Finally, we discuss $\mathrm{Ru}$ incorporation into $\mathrm{TaN}$ and the interaction with $\mathrm{Cu}$ adatoms.

\subsection{Ru and Cu Adatoms at Bare $\varepsilon$-TaN Surfaces}

\subsubsection{Adatom Adsorption}

$\mathrm{Ru}$ and $\mathrm{Cu}$ atoms are adsorbed at various unique sites on the most favourable low index $\varepsilon$-TaN surfaces (( $\left.\begin{array}{lll}1 & 1 & 0\end{array}\right),\left(\begin{array}{lll}1 & 1 & 1\end{array}\right)$ and $\left(\begin{array}{lll}1 & 0 & 0\end{array}\right)$ ) and the stable sites found after relaxation along with schematic pathways connecting them are shown in Figure 2 This figure also includes the top and side views of the most favourable minimum geometries of the respective surfaces. For these geometries, the adatom binding energies, selected interatomic distances ( $\mathrm{Cu}-\mathrm{Ta}$, $\mathrm{Ru}-\mathrm{Ta}, \mathrm{Cu}-\mathrm{N}$ and $\mathrm{Ru}-\mathrm{N}$ ) and bader charge on the adatom are listed in Table 2. The corresponding values for all the computed minima and their geometries are given in section S4.1 of ESI. $\dagger$

For the ( $\left.\begin{array}{lll}1 & 1 & 0\end{array}\right)$ surface, shown in Figure 2al, site A, a 5 fold hollow site coordinated by $3 \mathrm{Ta}$ and $2 \mathrm{~N}$ atoms, is the most favourable adsorption site for both $\mathrm{Ru}$ and $\mathrm{Cu}$ adatoms. At this site, the $\mathrm{Ru}$ adatom binds with an energy of $-4.95 \mathrm{eV}$, which is $2.13 \mathrm{eV}$ stronger than that of the $\mathrm{Cu}$ adatom. The $\mathrm{Cu}-\mathrm{N}$ and $\mathrm{Ru}-\mathrm{N}$ distances are very similar (1.9 ̊), but the Ru-Ta distance is about $0.2 \AA$ shorter than the $\mathrm{Cu}$-Ta distance. From the Bader charge analysis we find that both $\mathrm{Cu}$ and $\mathrm{Ru}$ adatoms are oxidized with net computed Bader charges of 0.5 and $0.2|\mathrm{e}|$, respectively (see Table 2$)$. This is due to the electron affinity differences between $\mathrm{Cu} / \mathrm{Ru}$ and $\mathrm{Ta} / \mathrm{N}$. On the ( $\left.\begin{array}{lll}1 & 1 & 1\end{array}\right)$ surface, site B, a wide hollow site between a pair of $\mathrm{N}$ and $\mathrm{Ta}$ atoms, is more favoured by both $\mathrm{Ru}$ and $\mathrm{Cu}$ adatoms. 
Table 2 Binding energies, average distances and valence electronic charge of $\mathrm{Cu}$ and $\mathrm{Ru}$ adatoms on the low index surfaces of $\varepsilon$-TaN. $d(X-Y)$ gives the average bond length between the neighbouring $X$ and $Y$ species in the corresponding minimum geometries. $Q(X)$ gives the computed charge of atom $X$ according to the Bader charge partitioning scheme.

\begin{tabular}{|c|c|c|c|c|c|c|c|c|c|c|c|}
\hline \multirow[t]{2}{*}{ Surface } & \multirow[t]{2}{*}{ Sites } & \multicolumn{2}{|c|}{$\mathrm{E}_{\text {bind }}[\mathrm{eV} / \mathrm{ads}]}$. & \multicolumn{6}{|c|}{ Interatomic distance $[\AA]$} & \multirow[t]{2}{*}{$\mathrm{Q}(\mathrm{Cu})$} & \multirow[t]{2}{*}{$\mathrm{Q}(\mathrm{Ru})$} \\
\hline & & $\mathrm{Cu}$ & $\mathrm{Ru}$ & $\mathrm{Cu}-\mathrm{Cu}$ & $\mathrm{Ru}-\mathrm{Ru}$ & $\mathrm{Cu}-\mathrm{N}$ & Ru-N & $\mathrm{Cu}-\mathrm{Ta}$ & Ru-Ta & & \\
\hline \multicolumn{12}{|c|}{$1 \mathrm{Cu} / \mathrm{Ru}$ adatom } \\
\hline$\left(\begin{array}{lll}1 & 1 & 0\end{array}\right)$ & A & -2.82 & -4.95 & & & 1.9 & 1.9 & 2.8 & 2.6 & 10.5 & 7.8 \\
\hline$\left(\begin{array}{lll}1 & 1 & 1\end{array}\right)$ & B & -3.21 & -5.64 & & & 2.0 & 2.0 & 2.5 & 2.4 & 11.2 & 8.4 \\
\hline$\left(\begin{array}{lll}1 & 0 & 0\end{array}\right)$ & A & -3.26 & -5.67 & & & 2.1 & 2.1 & 2.7 & 2.6 & 11.1 & 8.3 \\
\hline \multicolumn{12}{|c|}{$2 \mathrm{Cu} / \mathrm{Ru}$ adatom } \\
\hline$\left(\begin{array}{lll}1 & 1 & 0\end{array}\right)$ & AA" & -2.98 & -5.04 & 2.4 & 2.4 & 2.0 & 2.0 & 2.8 & 2.8 & $10.6 / 10.6$ & $7.7 / 7.5$ \\
\hline \multirow[t]{2}{*}{$\left(\begin{array}{lll}1 & 1 & 1\end{array}\right)$} & $\mathrm{AB}$ & -3.04 & -5.37 & 3.8 & 4.0 & 2.5 & 2.6 & 2.6 & 2.4 & $11.2 / 11.3$ & $8.4 / 8.7$ \\
\hline & A2B & -2.96 & -5.53 & 2.4 & 2.4 & 2.0 & 2.0 & 2.7 & 2.6 & $11.0 / 11.1$ & $8.3 / 8.2$ \\
\hline \multirow[t]{2}{*}{$\left(\begin{array}{lll}1 & 0 & 0\end{array}\right)$} & AA'c & -3.37 & -5.64 & 2.7 & 3.0 & 2.1 & 2.0 & 2.7 & 2.7 & $11.0 / 11.1$ & $8.3 / 8.2$ \\
\hline & AA'a & -3.25 & -5.74 & 5.9 & 5.8 & 2.1 & 2.1 & 2.7 & 2.7 & $11.1 / 11.1$ & $8.3 / 8.3$ \\
\hline
\end{tabular}

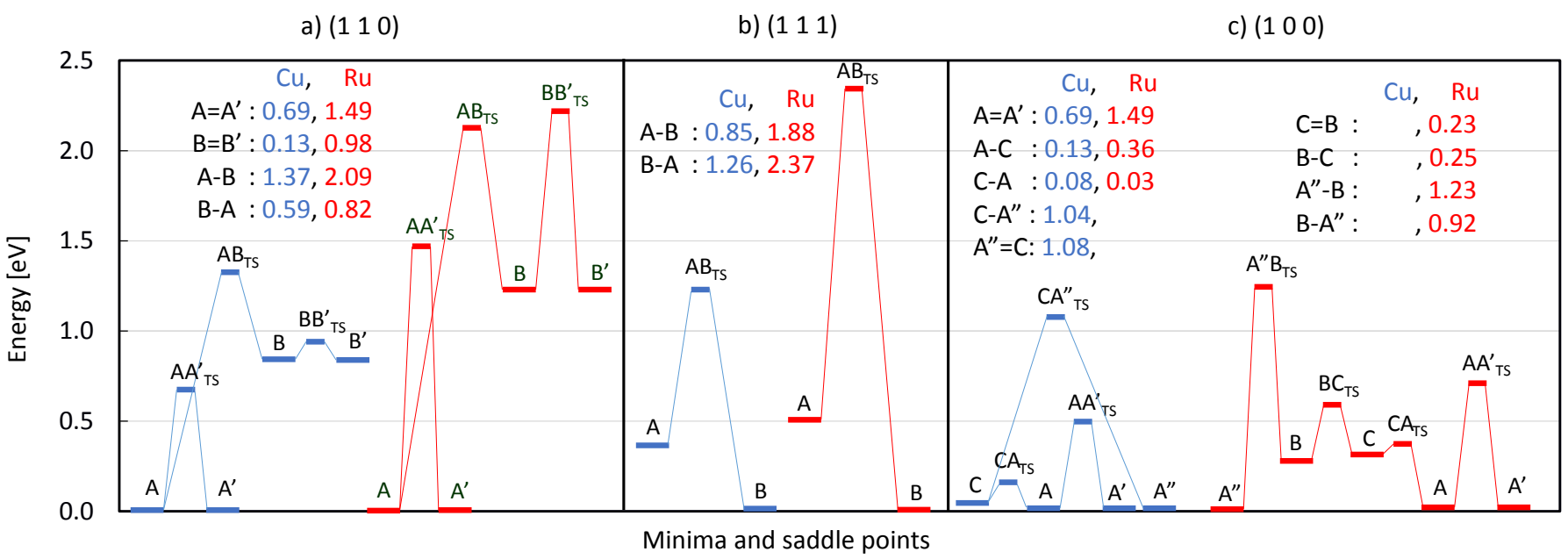

Fig. 3 Panels a), b) and c) shows the saddle points and activation energies for the on-surface hopping of the Cu/Ru adatoms on the (110), (1 11 ) and $\left(\begin{array}{lll}1 & 0 & 0\end{array}\right)$ surfaces of $\varepsilon$-TaN, respectively. The numbers and edges in blue correspond to Cu and those in red correspond to Ru.

Similar to the $\left(\begin{array}{lll}1 & 1 & 0\end{array}\right)$ surface, we find that the Ru adatom binds about $-2.43 \mathrm{eV}$ stronger than the $\mathrm{Cu}$ adatom. However, in contrast to the $\left(\begin{array}{lll}1 & 1 & 0\end{array}\right)$ surface we find that both $\mathrm{Cu}$ and $\mathrm{Ru}$ adatoms are reduced on this surface, Table 2 . The adatoms gain electrons from the neighbouring Ta atoms, which are not as oxidized as those in the $\left(\begin{array}{lll}1 & 1 & 0\end{array}\right)$ surface (see section S5 of ESI $\dagger$ for detailed analysis). On the $\left(\begin{array}{lll}1 & 0 & 0\end{array}\right)$ surface, site A, a three fold site coordinated by 2 $\mathrm{Ta}$ and $1 \mathrm{~N}$ atoms, is the lowest energy site for both $\mathrm{Ru}$ and $\mathrm{Cu}$ adsorption. Similar to the $\left(\begin{array}{lll}1 & 1 & 1\end{array}\right)$ surface, the $\mathrm{Cu}$ and $\mathrm{Ru}$ adatoms are partially reduced at this surface as evident from the computed Bader charges reported in Table 2

As the next step, the activation energies for adatom hops on these surfaces are shown in Figure 3 From the most stable site A on the (1 110$)$ surface, the $\mathrm{Cu}$ and Ru adatoms can hop to an adjacent identical site along the trench (site A') by overcoming activation energies of $0.69 \mathrm{eV}$ and $1.49 \mathrm{eV}$, respectively. Similarly, the adatoms can also hop back and forth between sites B and B' by overcoming just $0.13 \mathrm{eV}$ in the case of $\mathrm{Cu}$ and $0.98 \mathrm{eV}$ in the case of $\mathrm{Ru}$. There is a relatively larger activation energy for the adatoms to diffuse from site A to site B $(1.37 \mathrm{eV}$ for $\mathrm{Cu}$ and $2.09 \mathrm{eV}$ for $\mathrm{Ru})$ when compared to the reverse hop $(0.59 \mathrm{eV}$ for $\mathrm{Cu}$ and 0.82 $\mathrm{eV}$ for $\mathrm{Ru}$ ) because site $\mathrm{A}$ is the most favourable binding site on this surface. The activation energies for hopping are larger for $\mathrm{Ru}$ than $\mathrm{Cu}$, which is expected due to the relatively stronger binding

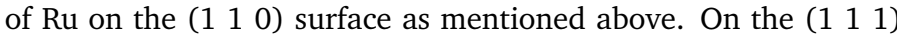
surface, we find that the activation energies for Ru migration from the most favourable site $\mathrm{B}$ to site $\mathrm{A}$ is about $2.37 \mathrm{eV}$ which is 1.11 $\mathrm{eV}$ larger than that of $\mathrm{Cu}$. On the $\left(\begin{array}{lll}1 & 0 & 0\end{array}\right)$ surface, the activation energy to hop from site A to A' along the trench (red arrow in Figure 22) is significantly smaller the combined activation energy for a hop across the trench (green arrows for $\mathrm{Cu}$ and blue arrows for Ru in Figure 26). Unlike the ( $\left.\begin{array}{lll}1 & 1 & 0\end{array}\right)$ and $\left(\begin{array}{lll}1 & 1 & 1\end{array}\right)$ surfaces, the activation energies for hops are almost comparable for both $\mathrm{Cu}$ and $\mathrm{Ru}$ adatoms on the $\left(\begin{array}{lll}1 & 0 & 0\end{array}\right)$ surface. 


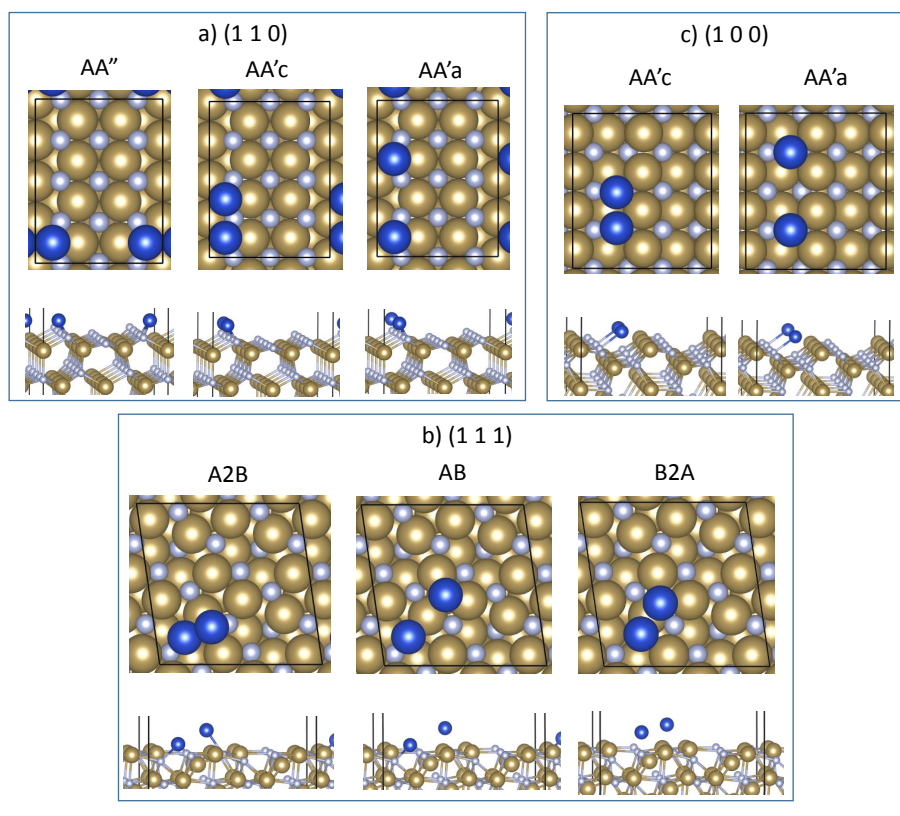

Fig. 4 Most favourable minimum energy geometries of 2 adatoms $(\mathrm{Cu} / \mathrm{Ru})$ at the selected low index surfaces of $\varepsilon$-TaN. Here A2B represents the geometry where the adatom at site $A$ moved towards the adatom at site $B$ and vice-versa. AA'c and AA'a represents 2 atom sites where the adatoms are close to each other and distant from each other, respectively. The Ta and $\mathrm{N}$ atoms are shown in ochre and light blue, respectively. The adatom ( $\mathrm{Cu}$ or $\mathrm{Ru}$ ) is shown in blue.

To summarize, relatively stronger adatom binding is observed

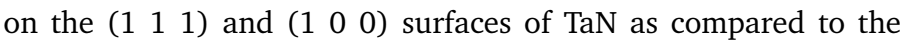
(1 110 ) surface. Ru binds significantly stronger than $\mathrm{Cu}$ on the TaN surfaces. The lowest activation energies for on-surface diffusion are observed on the (lllll 100$)$ surface followed by the $\left(\begin{array}{lll}1 & 1 & 0\end{array}\right)$ and ( $\left.\begin{array}{lll}1 & 1 & 1\end{array}\right)$ surfaces. We also find that the $\mathrm{Ru}$ and $\mathrm{Cu}$ adatoms are oxidized on the (1 110$)$ surface, while they are reduced on the (lll $\left.\begin{array}{ll}1 & 1\end{array}\right)$ and ( $\left.\begin{array}{lll}1 & 0 & 0\end{array}\right)$ surfaces. Clearly, the (llll $\left.\begin{array}{lll}1 & 1 & 0\end{array}\right)$ surface behaves differently from the other two surfaces.

\subsubsection{Adatom Adsorption}

As the next step $2 \mathrm{Cu} / \mathrm{Ru}$ adsorption is studied on the most favourable low index surfaces. This is carried out in such a way that the first adatom is placed at the most favourable site on the respective surface and the second adatom is placed at the remaining sites adjacent to the first adatom. The binding energies, selected interatomic distances and adatom charges in the most favourable minimum geometries are listed in Table 2 and the corresponding geometries are shown in Figure 4. This figure also includes the geometries (AA'a and $A A^{\prime} c$ ) that are used to compute activation energies of association. AA'c and AA'a refer to geometries where $A^{\prime}$ is adjacent to $A$ and $A^{\prime}$ is away from $A$, respectively. The energies and geometries of the other minima are discussed in section S4.2 of ESI. $\dagger$

On the (1 110 ) surface, the most favourable binding is observed when the $\mathrm{Cu}$ or $\mathrm{Ru}$ atoms are adsorbed at sites $\mathrm{A}$ and $\mathrm{A}^{\prime \prime}\left(\mathrm{AA}^{\prime}\right)$ which are located adjacent to each other on the $(1 \times 4)$ supercell of TaN ( $\left.\begin{array}{lll}1 & 1 & 0\end{array}\right)$ surface (see Figure 4 a). Comparing the results of the 2 adatom case with the 1 adatom case, we do not find a signifi- cant increase in the binding energies per $\mathrm{Cu} / \mathrm{Ru}$ atom even though the two adatoms are close to each other. Therefore the adatomadatom interaction must be small. Similar to the 1 adatom case, the $\mathrm{Ru}$ and $\mathrm{Cu}$ adatoms are oxidized at all sites on this surface. On the (lllll 111 ) surface the two adatoms are first adsorbed at sites $A$ and $B(A B)$ to represent the separated state. To examine the association of the adatoms to form $\mathrm{Cu}-\mathrm{Cu} / \mathrm{Ru}-\mathrm{Ru}$ bonds, two geometries are constructed by keeping one of the adatoms at either site A or B and the other immediately next to it (A2B and B2A in Figure 4). It appears that $\mathrm{Cu}$ adatoms prefer to stay separated ( $\mathrm{AB}$ is more stable than $\mathrm{A} 2 \mathrm{~B}$ ) while the $\mathrm{Ru}$ adatoms prefer to associate close to site $B$ ( $A 2 B$ more stable than $A B$ ). On the ( $\left.\begin{array}{lll}1 & 0 & 0\end{array}\right)$ surface, the associated state AA'c is the most favourable 2 atom site for $\mathrm{Cu}$ adatoms whereas the separated state AA'a is the most favourable for $\mathrm{Ru}$ adatoms. Similar to the 1 adatom case, the adatoms at ( $\left.\begin{array}{lll}1 & 1 & 1\end{array}\right)$ and (lll 100$)$ surfaces are moderately reduced or remain neutral.

We have computed the activation energies for adatom association at these surfaces. For ( $\left.\begin{array}{lll}1 & 1 & 0\end{array}\right)$ and $\left(\begin{array}{lll}1 & 0 & 0\end{array}\right)$ surfaces, the migration of the adatom at site A' from AA'a to AA'c could be regarded as adatom association. For the (lllll 111 ) surface this will be the migration of adatom at site $A$ towards the adatom at site $B$ (AB to $A 2 B)$ or vice-versa ( $A B$ to $B 2 A)$. On the $\left(\begin{array}{lll}1 & 1 & 0\end{array}\right)$ surface, $C u$ prefers the separated state (AA'a) while the Ru prefers the associated state (AA'c). When initialized from the separated state (AA'a), activation energies of about $0.73 \mathrm{eV}$ and $1.32 \mathrm{eV}$ are needed to reach the associated state. For $\mathrm{Cu}$ and $\mathrm{Ru}$, the reverse process requires energies of about $0.57 \mathrm{eV}$ and $1.60 \mathrm{eV}$. On the $\left(\begin{array}{lll}1 & 1 & 1\end{array}\right)$ surface, while $\mathrm{Cu}$ adatoms prefer the separated state, the activation energy needed for them to associate is just $0.16 \mathrm{eV}$. While Ru adatoms prefer the associated state, the activation energy to separate is $0.47 \mathrm{eV}$. In contrast to the (lllll 110 ) surface, the $\mathrm{Cu}$ and $\mathrm{Ru}$ adatoms on the ( $\left.\begin{array}{lll}1 & 0 & 0\end{array}\right)$ surface prefer the associated and separated states, respectively. Activation energies of 0.48 and $0.64 \mathrm{eV}$ are required for the $\mathrm{Cu}$ and $\mathrm{Ru}$ adatoms to associate on this surface.

To summarize, similar to the 1 adatom case, the adatoms bind

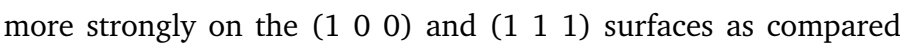
to the $\left(\begin{array}{lll}1 & 1 & 0\end{array}\right)$ surface. Further, the adatoms are either metallic or

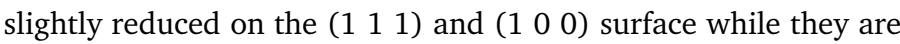
oxidized on the (lllll 110$)$ surface due to the different numbers of Fand S-type Ta atoms on these surfaces. The Cu adatoms at (llllllll surface prefer to stay separated and offer the highest activation energy towards association when compared with the other surfaces. Therefore, $\mathrm{Cu}$ atoms may wet on the (llll 110$)$ surface as compared to the other low-index surfaces. Thus, we chose to use the (llll 110$)$ surface for Ru passivation and doping studies.

\subsection{Cu at Hexagonal Ruthenium}

Before investigating the interaction of $\mathrm{Cu}$ at $\mathrm{Ru}$ doped and $\mathrm{Ru}$ passivated surfaces, we have to understand the interaction between $\mathrm{Cu}$ adatoms and the bare Ru surface.

Figure S4a in ESI $\dagger$ shows the bare Ru(lo 0 1 $)$ surface along with the stable binding sites for $\mathrm{Cu}$ adsorption namely $\mathrm{A}, \mathrm{B}$ and $\mathrm{C}$, where $\mathrm{A}$ is a hcp site, $\mathrm{B}$ is a hollow site and $\mathrm{C}$ is an atop $\mathrm{Ru}$ site. The binding energies and valence charge of one $\mathrm{Cu}$ adatom at these sites are 


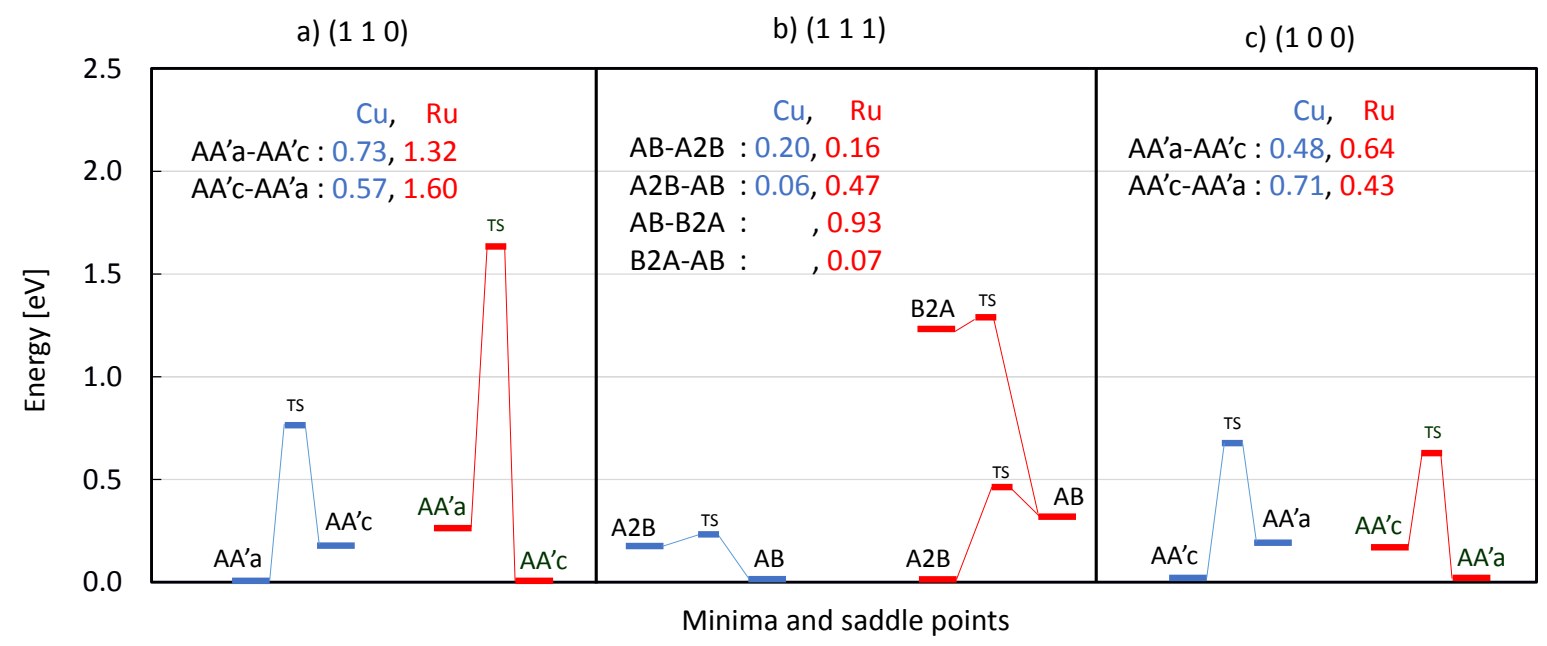

Fig. 5 Panels a), b) and c) shows the saddle points and activation energies for the on-surface association of two $\mathrm{Cu} / \mathrm{Ru}$ adatoms on the (110), (111) and $\left(\begin{array}{lll}1 & 0 & 0\end{array}\right)$ surfaces of $\varepsilon$-TaN, respectively. The numbers and edges in blue correspond to $\mathrm{Cu}$ and those in red correspond to Ru.

Table 3 Binding energies of $\mathrm{Cu}$ adatoms on the $\left(\begin{array}{lll}0 & 0 & 1\end{array}\right)$ surface of $\mathrm{Ru}$.

\begin{tabular}{lcc}
\hline Sites & $\mathrm{Q}(\mathrm{Cu})$ & $\mathrm{E}_{\text {bind }}[\mathrm{eV}]$ \\
\hline & 1 Cu adsorption & \\
A (HCP) & 10.9 & -3.18 \\
B (HOLLOW) & 10.9 & -3.14 \\
C (ATOP) & - & - \\
A $_{\text {exch }}$ & 10.9 & -2.07 \\
B $_{\text {exch }}$ & 11.0 & -1.52 \\
& & \\
& 2 Cu adsorption & \\
AAc & $10.9 / 10.9$ & -3.26 \\
AAa & $10.9 / 10.9$ & -3.16 \\
BBc & $10.9 / 10.9$ & -3.22 \\
BBa & $10.9 / 10.9$ & -3.11 \\
\hline
\end{tabular}

given in Table 3 . Adsorption of $\mathrm{Cu}$ adatoms on $\mathrm{Ru}\left(\begin{array}{lll}0 & 0 & 1\end{array}\right)$ surface has been studied previously by Qu and co-workers ${ }^{29157}$ using DFT and ultrasoft pseudopotentials. However, they did not compute the hopping/association activation energy or sub-surface diffusion activation energy of the adatoms, which we have focused on in this section.

We have also included the geometries where the $\mathrm{Cu}$ adatom from a hcp and a hollow site is exchanged with a surface Ru atom labelled as $\mathrm{A}_{\text {exch }}$ and $\mathrm{B}_{\text {exch }}$, respectively. The $\mathrm{Cu}$ atom was not stable at the atop $\mathrm{Ru}$ site. The $\mathrm{Cu}$ adatom binds with similar binding energies at sites $\mathrm{A}$ and $\mathrm{B}$ in the range of $-3.14 \mathrm{eV}$ to $-3.18 \mathrm{eV}$ which is comparable to the TaN surfaces discussed earlier. However, the binding energy decreases considerably (-1.52 to $-2.07 \mathrm{eV}$ ) when the $\mathrm{Cu}$ atom is exchanged with a surface $\mathrm{Ru}$ atom. The $\mathrm{Cu}$ adatom remains metallic on the Ru surface. The activation energies involved in the on-surface hop and sub-surface exchange of $\mathrm{Cu}$ adatoms are given in Figure 6 and the minimum geometries used in the corresponding CI-NEB calculations can be seen in Figure S4b of ESI. $\dagger$ We find that the activation energy for facile diffusion of a $\mathrm{Cu}$ adatom on $\operatorname{Ru}\left(\begin{array}{lll}0 & 0 & 1\end{array}\right)$ is in general very small. The activation energy to hop from a hcp to a hollow site (A to B) is only 0.11 $\mathrm{eV}$ and the reverse hop is just $0.07 \mathrm{eV}$ supporting the fact that the hcp site is slightly more preferred by the $\mathrm{Cu}$ adatom. In contrast, the activation energy for the exchange process is very large. The activation energy to exchange from a hcp site is about $3.07 \mathrm{eV}$ and from a hollow site is $2.89 \mathrm{eV}$. The reverse exchange processes have relatively smaller activation energies which are about $1.97 \mathrm{eV}$ for the hcp site and $1.27 \mathrm{eV}$ for the hollow site. In any case, these exchange processes are unlikely due to the high activation energies impeding them.

In the next step two copper atoms are adsorbed on the Ru(l 001$)$ surface and we consider two cases. In the first case, the two copper atoms are bound only to hcp sites (AAa and AAc) and in the second case they are bound only to hollow sites (BBa and $\mathrm{BBc}$ ). The corresponding geometries used for this study are shown in Figure S4c of $\mathrm{ESI} \dagger$ and the energies are listed in Table 3. The geometries at sites $\mathrm{AAa}$ and $\mathrm{BBa}$ represent cases where the adatoms are separated and those at $\mathrm{AAc}$ and $\mathrm{BBc}$ are cases where the adatoms are adjacent to each other. The binding energies per adsorbed $\mathrm{Cu}$ were found to be very similar in the range of $-3.11 \mathrm{eV}$ to $-3.26 \mathrm{eV}$. Therefore, we studied the activation energies separating them as indicated by the arrows in Figure S4c of ESI. $\dagger$ A copper atom can diffuse along the surface via two types of hops - hcp to hollow and hollow to hcp. So to migrate from one hcp site to another the adatom must first hop to a hollow site and then to the hcp destination site which involves crossing two activation barriers. From Figure 6 we find the greatest activation energies for the first hop from the associated states $\mathrm{AAc}(0.26 \mathrm{eV})$ and $\mathrm{BBc}(0.22 \mathrm{eV})$ and the lowest activation energies for the second hop toward the same states $(0.01 \mathrm{eV}$ and 0.05 $\mathrm{eV})$. The $\mathrm{Cu}$ adatoms are therefore very mobile on the $\mathrm{Ru}\left(\begin{array}{lll}0 & 0 & 1\end{array}\right)$ surface and prefer to associate.

\subsection{Ru Passivated TaN Surfaces}

In this section, adsorption and diffusion of $\mathrm{Cu}$ adatoms on $\mathrm{Ru}$ passivated TaN(1 100$)$ surfaces will be studied. A discussion on the adsorption of $\mathrm{Ru}$ adatoms that resulted in the formation of a passivated layer is given in section S7 of ESI. $\dagger$ For our purposes, we will perform the $\mathrm{Cu}$ adsorption and diffusion calculations on $1 \mathrm{ML}$ 

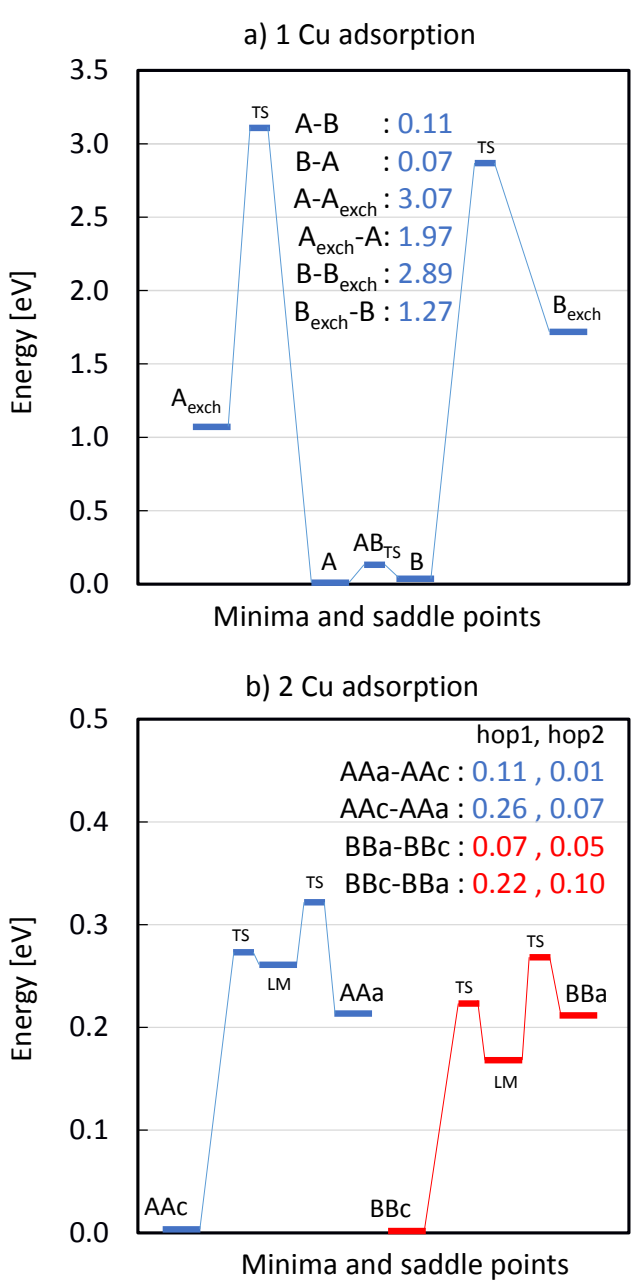

Fig. 6 Panels a) and b) show the minima, saddle points and activation energies for the on-surface diffusion and association of $\mathrm{Cu} / \mathrm{Ru}$ adatoms on the $R u\left(\begin{array}{lll}0 & 0 & 1\end{array}\right)$ surface, respectively. Here, 'LM' refers to local minimum and 'TS' refers to transition state.

and 2 ML of Ru passivated TaN(1 10 ) surfaces (in Figures S11e and S11f of ESI $\dagger$ ).

\subsubsection{Cu Adatoms at 1 ML Ru passivated TaN( $\left.\begin{array}{lll}1 & 1 & 0\end{array}\right)$ surface}

From the three stable binding sites (A, B and C) shown in Figure $7 \mathrm{~A}$, the strongest binding is seen at site $\mathrm{B}$, a wide 3 fold site above a sub-surface Ta atom. The binding energies listed in Table 4 are moderately lower than that on the bare $\left(\begin{array}{lll}1 & 1 & 0\end{array}\right)$ surface suggesting that $\mathrm{Ru}$ passivation also promotes $\mathrm{Cu}$ binding. We did not find significant changes in the valence charge of the adsorbed $\mathrm{Cu}$ atom which indicates that there is no significant electron transfer between the $\mathrm{Cu}$ adatom and the $\mathrm{Ru}$ layer.

The on-surface hopping activation energies of a $\mathrm{Cu}$ adatom between sites A-B and B-C (shown in Figure 83) are in the range of $0.01 \mathrm{eV}-0.45 \mathrm{eV}$. The greatest activation energy of $0.45 \mathrm{eV}$ is found for the $\mathrm{Cu}$ atom to migrate from site $\mathrm{B}$ to site $\mathrm{C}$ and the lowest activation energy of $0.01 \mathrm{eV}$ is found for its diffusion from site A to $B$. These activation energies are comparatively larger than on the

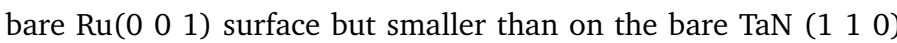
surface. We have also looked at the energies of sub-surface ad-
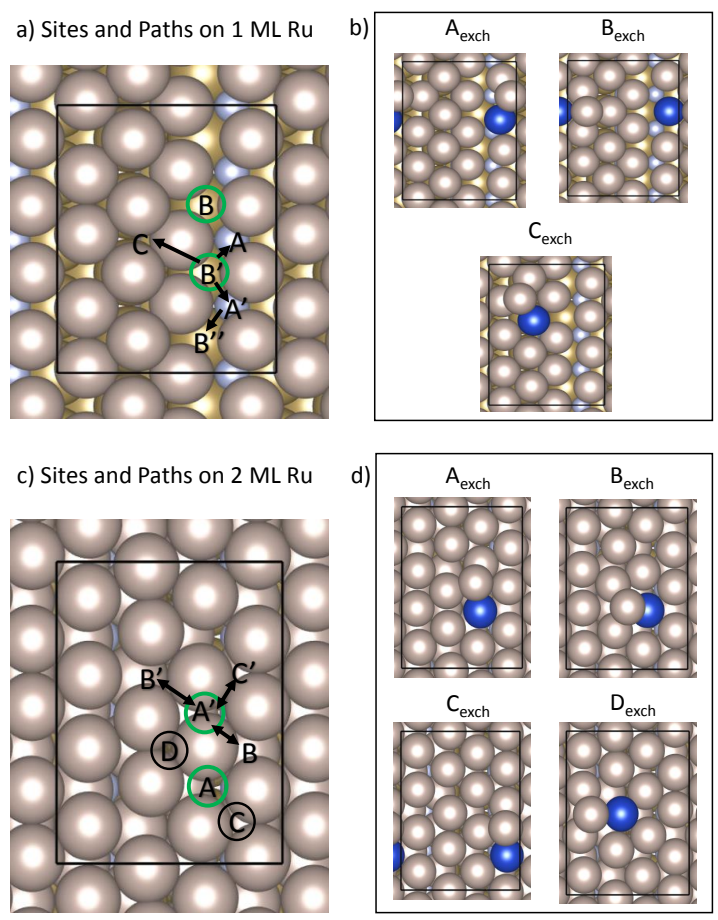

Fig. 7 Unique adsorption sites for $\mathrm{Cu}$ adsorption on 1 and $2 \mathrm{ML}$ of $\mathrm{Ru}$ passivated TaN $\left(\begin{array}{lll}1 & 1 & 0\end{array}\right)$ surface are shown in panels a and c, respectively. It also includes pathways to compute activation energies for association in two $\mathrm{Cu}$ adsorption, where the $\mathrm{Cu}$ sites in associated states are highlighted in green and the arrows indicate the pathway. Panels $b$ and $d$ show the geometries where a $\mathrm{Cu}$ adatom is adsorbed at sub-surface sites. The $\mathrm{Ta}, \mathrm{N}, \mathrm{Ru}$ and $\mathrm{Cu}$ atoms are shown in ochre, light blue, brown and blue, respectively.

sorption of the $\mathrm{Cu}$ adatom from the above mentioned stable sites, as shown in Figure 7p. All the sub-surface adsorption geometries had high energies and large diffusion barriers (see Figure $8 \mathrm{a}$ ) as compared to the corresponding on-surface adsorption geometries. More on this topic can be found in section S7 of ESI. $\dagger$

As the next step, adsorption of $2 \mathrm{Cu}$ is investigated where the geometry at site BB' (combined site notation: one adatom at $\mathrm{B}$ and the other at B') is found to be the most favourable where the $\mathrm{Cu}$ atoms are at a distance of $2.5 \AA$. Details of the other geometries are discussed in section S7 of ESI. $\dagger$ Compared to the $1 \mathrm{Cu}$ adsorption case, we find that the binding energies have decreased slightly, probably due to the additional $\mathrm{Cu}-\mathrm{Cu}$ interaction and associated surface rearrangements.

We have chosen the geometry at site BB' as the associated state (shown by green circles in the figure) and computed the activation energies associated with the diffusion of the second $\mathrm{Cu}$ atom from site B' to sites A, C and B". The forward activation energies from $\mathrm{BB}^{\prime}$ to the other sites are in the range of $0.35-0.48 \mathrm{eV}$ and the reverse activation energies are significantly lower as shown in Figure $8 \mathrm{p}$. This suggests that the $\mathrm{Cu}$ adatoms, in addition to diffusing on the surface, prefer to associate more so than on the bare TaN (1 110 ) surface.

\subsubsection{Cu Adatoms at 2 ML Ru passivated TaN( $\left.\begin{array}{lll}1 & 1 & 0\end{array}\right)$ surface}

On the $2 \mathrm{ML}$ of Ru passivated TaN(1 110$)$ surface shown in Figure 7k, the two fold Ru coordinated site A is found to be the most 
a) $1 \mathrm{Cu}$ adsorption

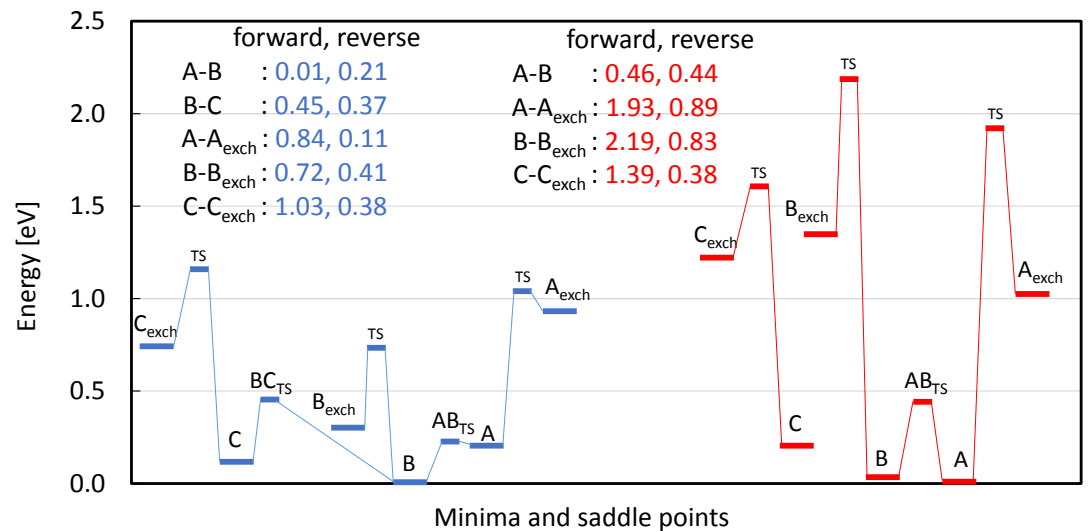

b) 2 Cu adsorption

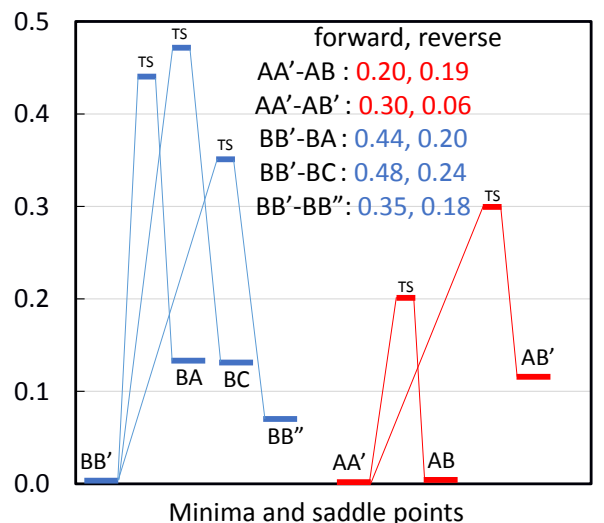

Fig. 8 Panels a) and b) show the minima, saddle points and activation energies for the on-surface/ subsurface diffusion of 1 Cu adatom and association of $2 \mathrm{Cu}$ adatoms on the Ru passivated TaN surfaces, respectively. Here, blue and red colors represent $1 \mathrm{ML}$ and $2 \mathrm{ML}$ of Ru passivated surfaces, respectively.

Table 4 Binding energies and activation energies for the diffusion of $\mathrm{Cu}$ adatoms on 1 and 2 ML of Ru passivated TaN (1 110$)$ surfaces. A '-' for the $E_{\text {bind }}$ indicates that the respective geometry is found to be unstable and a '-' for $E_{\text {activation }}$ indicates that we could not find a transition state connecting the minima.

\begin{tabular}{|c|c|c|c|c|}
\hline Adatoms & Sites & $\mathrm{Q}(\mathrm{Cu})$ & $\mathrm{E}_{\text {bind }}[\mathrm{eV}]$ & $\mathrm{d}(\mathrm{Cu}-\mathrm{Cu})[\AA]$ \\
\hline & & $1 \mathrm{ML} \mathrm{Ru}$ & & \\
\hline \multirow[t]{3}{*}{$1 \mathrm{Cu}$} & A (3 fold atop N) & 10.9 & -3.24 & \\
\hline & B (3 fold atop Ta) & 11.0 & -3.44 & \\
\hline & $C(2$ fold $)$ & 10.9 & -3.35 & \\
\hline \multirow[t]{5}{*}{$2 \mathrm{Cu}$} & BB' & $11.0 / 11.0$ & -3.60 & 2.5 \\
\hline & BA & $11.0 / 11.0$ & -3.48 & 2.6 \\
\hline & BC & $11.0 / 10.9$ & -3.49 & 2.9 \\
\hline & BB" & $11.0 / 10.9$ & -3.52 & 5.2 \\
\hline & & $2 \mathrm{ML} \mathrm{Ru}$ & & \\
\hline \multirow[t]{4}{*}{$1 \mathrm{Cu}$} & A (2 fold) & 11.0 & -3.44 & \\
\hline & B (3 fold wide) & 11.0 & -3.42 & \\
\hline & C (3 fold hcp) & 10.9 & -3.18 & \\
\hline & D (3 fold hollow) & 10.9 & -3.13 & \\
\hline \multirow[t]{5}{*}{$2 \mathrm{Cu}$} & $\mathrm{AA}^{\prime}$ & $11.0 / 10.9$ & -3.43 & 2.7 \\
\hline & $\mathrm{AB}$ & $11.0 / 11.0$ & -3.43 & 2.5 \\
\hline & AC & $11.0 / 10.9$ & -3.35 & 2.4 \\
\hline & $\mathrm{AB}^{\prime}$ & $10.9 / 11.0$ & -3.31 & 4.8 \\
\hline & AC' & $11.0 / 10.9$ & -3.30 & 4.6 \\
\hline
\end{tabular}

favourable. Similar to the 1 ML case, there is no significant charge transfer between the $\mathrm{Cu}$ and $\mathrm{Ru}$ atoms.

The activation energies for the $\mathrm{Cu}$ adatom to hop from the most favourable site A to site B is computed to be $0.46 \mathrm{eV}$ and the activation energy for the reverse process is almost the same as shown in Figure 7 $\mathrm{A}$. Pathways connecting site A to sites $C$ and D could not be found in our investigation. The sub-surface exchange geometries given in Figure $7 \mathrm{~d}$ are found to be approximately $1 \mathrm{eV}$ lower in binding energy than the corresponding on-surface adsorption cases. More details can be found in section S7 of ESI. $\dagger$

For $2 \mathrm{Cu}$ adsorption, the first $\mathrm{Cu}$ is placed at site $\mathrm{A}$ and the second $\mathrm{Cu}$ is placed at sites B, C, A', B' and C' (see Figure 77). The binding energies per $\mathrm{Cu}$ are in the range of $-3.30 \mathrm{eV}$ to $-3.43 \mathrm{eV}$ which is comparable to the $1 \mathrm{Cu}$ adsorption energies on this surface.

The association activation energies are computed by keeping the geometry at $\mathrm{AA}^{\prime}$ as the starting point and moving the $\mathrm{Cu}$ at $\mathrm{A}^{\prime}$ to sites B, B' and C' as indicated by arrows in Figure 7 7 . We find that the two atom sites $A A^{\prime}$ and $A B^{\prime}$ are equally favourable. For the minimum energy pathways connecting $A A^{\prime}$ with $A B$ ', the forward activation energy is greater than the reverse activation energy in dicating a preference for $\mathrm{Cu}$ atoms to coordinate with each other.

To summarize, the $\mathrm{Cu}$ adatoms bind more strongly at the $\mathrm{Ru}$ passivated surfaces as compared to the bare $\mathrm{Ru}$ and the bare TaN $\left(\begin{array}{lll}1 & 1 & 0\end{array}\right)$ surfaces. We also did not observe any significant charge transfer between the $\mathrm{Cu}$ and $\mathrm{Ru}$ atoms. The on-surface $\mathrm{Cu}$ diffusion activation energies are moderately larger than those on bare $\mathrm{Ru}$, but significantly smaller than those on the bare TaN $\left(\begin{array}{lll}1 & 1 & 0\end{array}\right)$ surface. Therefore, the $\mathrm{Cu}$ adatoms are mobile on this surface and might show a preference toward association like they do in the bare Ru surface.

\subsection{Ru doped TaN}

As an alternative to the Ru passivated surfaces we will now study the Ru doped TaN ( 1110$)$ surfaces as a single barrier+liner material. All calculations for $\mathrm{Cu}$ adsorption on Ru-doped TaN ( $\left.\begin{array}{lll}1 & 1 & 0\end{array}\right)$ were carried out using a $(2 \times 4)$ supercell in order to eliminate any finite size effects caused by Ru doping of the $(1 \times 4)$ supercell. However, as will be shown in this section, the effects of $\mathrm{Ru}$ in the surface are very localised and thus it is possible to use the smaller (1×4) supercell for the NEB calculations. Although Ru is suitable for copper electroplating, it does not function well, by itself, as a diffusion barrier material. The Ru passivated TaN surfaces studied in the previous section were found to have small activation energies for the on-surface diffusion of copper atoms and may allow $\mathrm{Cu}$ association. Therefore the possibility of tuning the TaN surface to allow wetting of $\mathrm{Cu}$ through doping with $\mathrm{Ru}$, while retaining the barrier properties of TaN, is the focus of this section. Ta atoms from two surface sites are replaced with Ru as shown in Figure $9 \mathrm{~g}$ to determine the more favourable doping site. 
a)

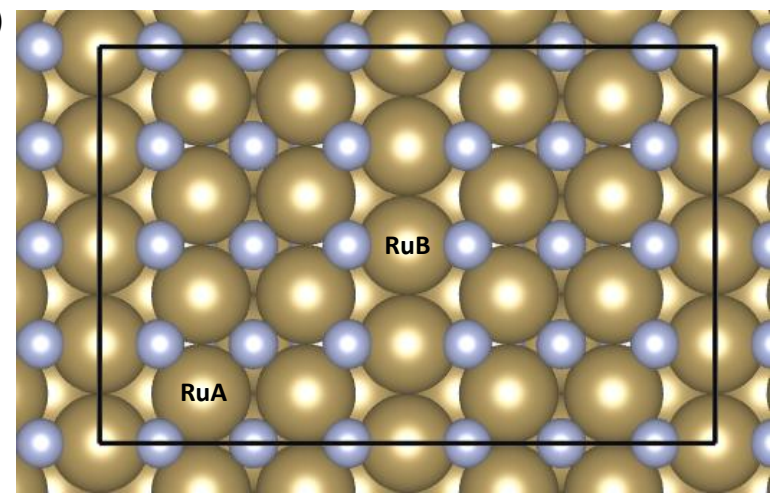

b)

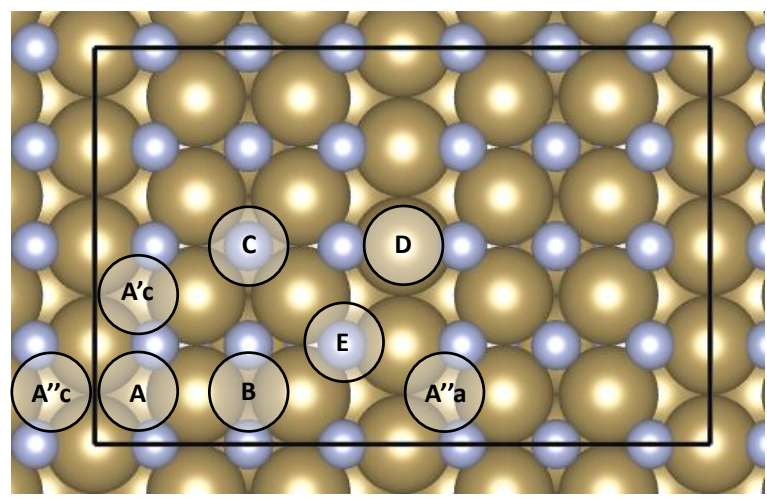

Fig. 9 a) Ru-doping sites and b) $\mathrm{Cu}$ adsorption sites on the $\mathrm{TaN}\left(\begin{array}{ll}1 & 1\end{array}\right)$ surface. The Ta and $\mathrm{N}$ atoms are shown in ochre and light blue, respectively.
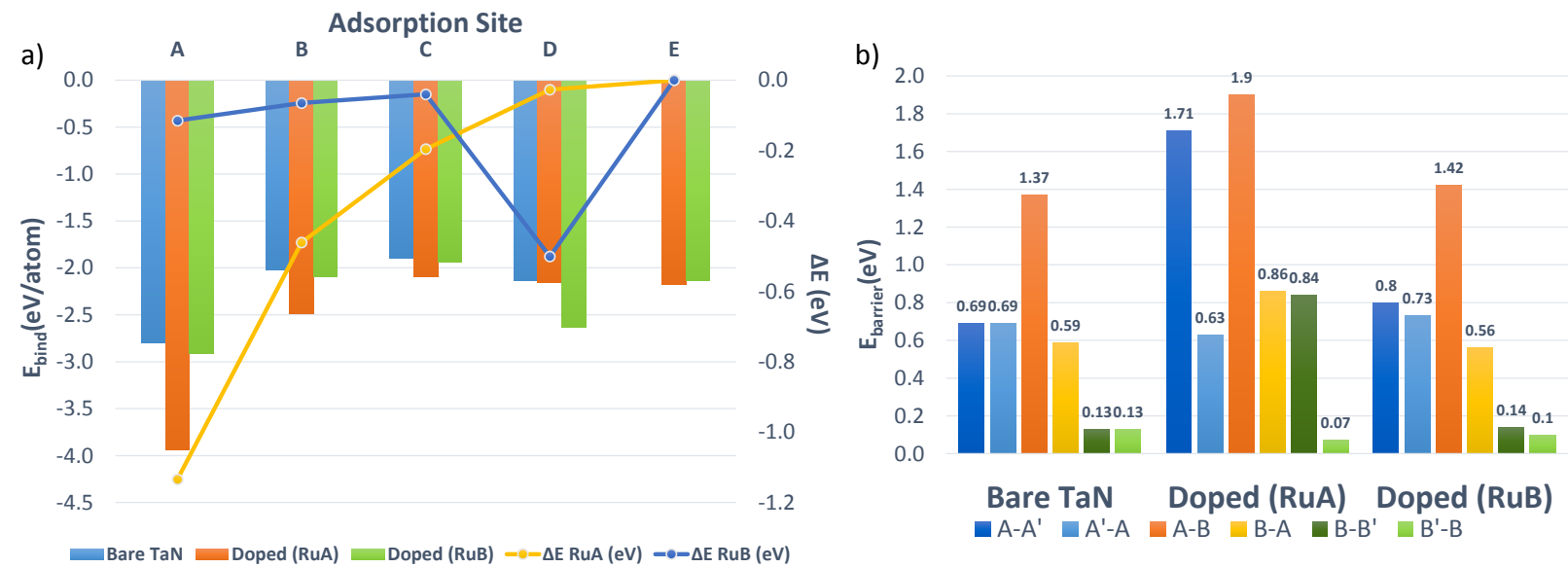

Fig. 10 Comparing changes in a) adsorption energies and b) activation energies between bare $(2 \times 4)$ TaN and Ru-doped ( $2 \times 4)$ TaN for each adsorption site.

RuA replaces a surface Ta atom (S type) coordinated to 4 surface $\mathrm{N}$ atoms while RuB replaces a surface Ta atom (F type) that is coordinated to 2 surface $\mathrm{N}$ atoms. The TaN surface doped with $\mathrm{RuB}$ was found to be $2.34 \mathrm{eV}$ more stable than that doped with RuA. Charge analysis of the surface shows that the charges on RuA and $\mathrm{RuB}$ are 7.1 and 7.5 respectively. This difference in Ru oxidation is likely the cause of the different surface energies. Details of the surface charges are shown in section S5 of ESI. $\dagger$ The introduction of Ru into the surface did not affect the TaN surface lattice considerably.

\subsubsection{Adatom Adsorption on Ru-doped TaN( $\left.\begin{array}{lll}1 & 1 & 0\end{array}\right)$}

On the bare $(2 \times 4)$ supercell of the TaN $\left(\begin{array}{lll}1 & 1 & 0\end{array}\right)$ surface, five unique $\mathrm{Cu}$ adsorption sites (A, B, C, D and E) were identified as shown in Figure $9 \mathrm{p}$. The binding energies of a $\mathrm{Cu}$ adatom at these five sites on the bare $(2 \times 4)$ surface as well as on the doped surfaces are compared in Figure 10 and the corresponding geometries for the most favourable site on RuA and RuB doped TaN surfaces are given in Figure 11 All other geometries are shown in section S8 of ESI. $\dagger$

Binding energies for $\mathrm{Cu}$ at the different sites range from $-2.01 \mathrm{eV}$ to $-3.93 \mathrm{eV}$ for the RuA doped surface, from $-1.94 \mathrm{eV}$ to $-2.92 \mathrm{eV}$ for the RuB doped surface compared to $-1.90 \mathrm{eV}$ to $-2.80 \mathrm{eV}$ for the bare surface. Overall, site $\mathrm{A}$ is the most stable and site $\mathrm{C}$ is the least

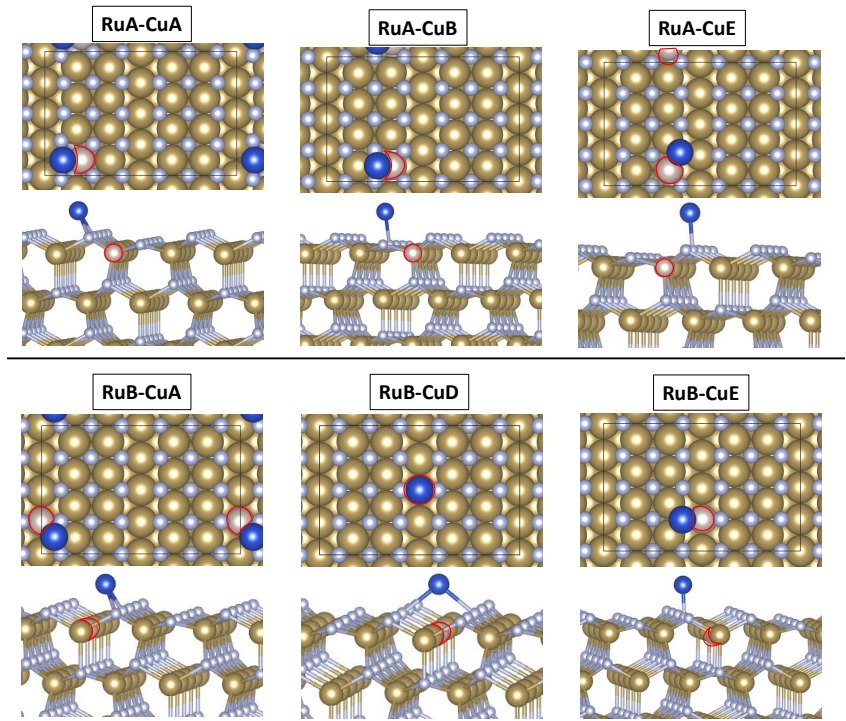

Fig. 11 Adsorption Geometries of most favourable $1 \mathrm{Cu}$ atom on RuAdoped RuB-doped $\mathrm{TaN}\left(\begin{array}{lll}1 & 1 & 0\end{array}\right)$. The Ta, N, Ru and $\mathrm{Cu}$ atoms are shown in ochre, light blue, brown and blue, respectively. $\mathrm{Ru}$ atoms are highlighted with a red border. 

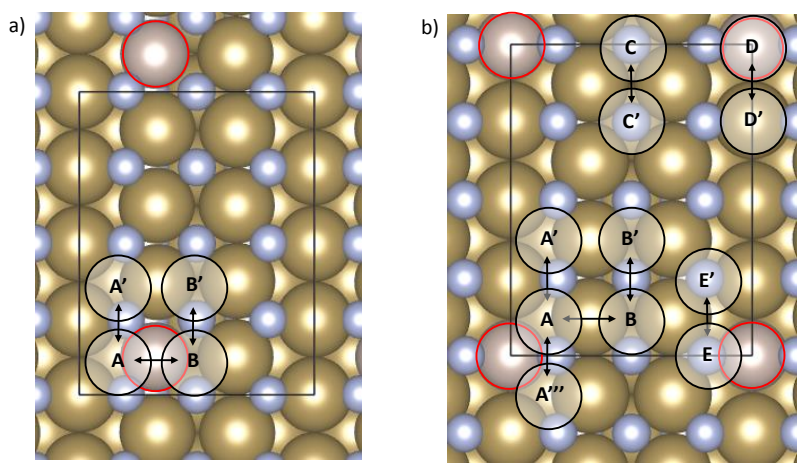

Fig. 12 Migration pathways of $\mathrm{Cu}$ adatoms on both doped surfaces a)RuA and b)RuB. The Ta, N, Ru and $\mathrm{Cu}$ atoms are shown in ochre, light blue, brown and blue, respectively. Ru atoms are highlighted with a red border.

stable for $\mathrm{Cu}$ adsorption on all the three surfaces. It is evident from Figure $10 \mathrm{a}$ that the $\mathrm{Cu}$ adatom binds slightly more strongly on the $\mathrm{Ru}$ doped TaN surfaces as compared to the bare TaN surface. The figure also shows the binding energy difference $(\Delta \mathrm{E})$ between the bare and Ru doped surfaces from which the largest change for RuA and RuB doped surfaces is found to have occurred at the sites $\mathrm{A}$ $(1.13 \mathrm{eV})$ and $\mathrm{D}(0.50 \mathrm{eV})$, respectively. RuA doped surface shows enhanced $\mathrm{Cu}$ binding at sites $\mathrm{A}, \mathrm{B}, \mathrm{C}$ and $\mathrm{E}$ as compared to RuB doped surface, whereas RuB doped surface shows enhanced $\mathrm{Cu}$ binding at site $\mathrm{D}$ as compared to RuA doped surface. Therefore, it is clear from the $\Delta \mathrm{E}$ plot in Figure $10 \mathrm{a}$ that those $\mathrm{Cu}$ adsorption sites that are closer to the doped Ru atom show enhanced binding as compared to the bare surface. Bader charge analysis showed that the $\mathrm{Cu}$ adatom is always oxidized and that the charge of $\mathrm{Cu}$ is mostly independent of adsorption site and number of adatoms, although a correlation between binding energies and charge can be observed. The changes in charge are no larger than 0.2 electrons, however atoms that are more oxidised still have a larger binding energy. All $\mathrm{Cu}$ charges are shown in Table 5

To determine how the adsorption of $\mathrm{Cu}$ atom affects the surface atomic structure of the $\mathrm{Ru}$ doped surfaces, the Ta-N bond lengths near the $\mathrm{Cu}$ adsorption sites (Ta-N adsorbed) are compared to those near an equivalent distant site on the same surface (Ta-N distant) and to those near an equivalent site in the bare Ru doped surface (Ta-N bare). The range of distances for these three cases are displayed in Figure S12 of ESI. $\dagger$. The bond lengths of Ta-N distant are similar to those of Ta-N bare, while the Ta- $\mathrm{N}$ bonds near the adsorption sites appear somewhat elongated. However, the changes observed between any of the Ta- $\mathrm{N}$ bonds measured across all surfaces, bare and doped, are no more than 0.1-0.2 $\AA$. Therefore, this study shows that in terms of geometry the effect of $\mathrm{Cu}$ adsorption and Ru-doping is localised to the adsorption/doping sites.

Due to the localised effect of Ru doping, the CI-NEB calculations were carried out using the smaller $(1 \times 4)$ supercell of TaN ( 1110$)$. To facilitate this, the minimum geometries and binding energies for $1 \mathrm{Cu}$ adsorption were also computed on the smaller $(1 \times 4) \mathrm{su}$ percell and compared with the $(2 \times 4)$ supercell in Table 5 It can be seen that the binding energies are very similar for both supercells supporting the localized effect of Ru doping.
As the next step, the activation energies impeding the migration of a $\mathrm{Cu}$ adatom on the Ru doped surfaces were computed. Firstly, we determined the activation energies for migration from the most favourable site (A) to the closest non-equivalent site (B) for both RuA and RuB doped surfaces as shown in Figure 10 p and the corresponding pathways in Fig. $12 \mathrm{p}$. On the RuB surface there is only a small increase in the on-surface diffusion activation energies, connecting sites A-A', B-B' and A-B, compared to the bare surface. The large increase in the activation energy for migration for RuA can be attributed to Cu moving across a doped Ru instead of the Ta atom. The activation energies observed on the RuA surface may appear much more favourable compared to those found on the RuB surface, however this is a biased comparison. As the $\mathrm{Ru}$ atom is closer to the $\mathrm{Cu}$ atom in the adsorption sites $\mathrm{A}$ and $\mathrm{B}$ on the RuA surface than on the RuB surface, the activation energy will be more affected due to the stronger binding between $\mathrm{Cu}$ and $\mathrm{Ru}$ compared to $\mathrm{Cu}$ and $\mathrm{Ta}$. Therefore the effect of $\mathrm{Ru}$ in the surface should be studied on a larger model with a higher percentage of doping, which is beyond the scope of this paper and is the focus of ongoing work.

For our purposes, we studied in detail the migration pathways and the corresponding activation energies on the more favourable RuB surface. The particular migration pathways are shown in Fig. 12 , while the corresponding activation energies are listed in section S8 of ESI $\dagger$ and are also shown in Fig. 9 p. The forward and reverse activation energies in the table indicate the activation energies required for the $\mathrm{Cu}$ atom to migrate away from and towards the doped $\mathrm{Ru}$, respectively. We observe that it is more favourable for $\mathrm{Cu}$ adatom to move towards the doped $\mathrm{Ru}$ on the surface than away from it. Especially in the case of migration from site B to A (towards $\mathrm{Ru}$ ) where the activation energy is almost 2.5 times lower than the migration from A to B (away from Ru). No migration pathways connecting the endpoints C-C', D-D' and E-E' were found. For the migration pathway B-B', very small activation energies of around $0.10 \mathrm{eV}$ were found. The noted exception of this being the activation energy of $0.84 \mathrm{eV}$ required to move a $\mathrm{Cu}$ atom away from site B on the RuA surface, where the adatom is directly adjacent to the Ru atom. The activation energy for the exchange of a $\mathrm{Cu}$ atom with the doped $\mathrm{Ru}$ in the surface is also determined. For $\mathrm{Ru}$ to move out of the surface and $\mathrm{Cu}$ to take its place the activation energy needed is as high as $3.78 \mathrm{eV}$. The reverse process has an activation energy of just $1.88 \mathrm{eV}$. This indicates that Ru doping is unlikely to allow sub-surface $\mathrm{Cu}$ adsorption and diffusion which allows the barrier properties of TaN to be maintained.

\subsubsection{Adatom Adsorption on Ru-doped TaN}

In this section we investigate the adsorption of $2 \mathrm{Cu}$ atoms and the activation energy for $\mathrm{Cu}$ association on the Ru doped surfaces. The 2 adatom adsorption calculations are done in such a way that the first $\mathrm{Cu}$ atom is placed at site $\mathrm{A}$, which is the most favourable site, and the second $\mathrm{Cu}$ atom is placed at all the other sites shown in Figure $9 \mathrm{~b}$ and the geometry is relaxed. Figure 13 shows the geometries for 2 adatoms on the doped surfaces, while Table 5 presents the computed binding energies. The corresponding results from the bare and doped surfaces are listed in Table 5

As with the single adatom case, the binding energy per adatom 
Table 5 Binding Energies of $\mathrm{Cu}$ on Ru-doped $\operatorname{TaN}\left(\begin{array}{lll}1 & 1 & 0\end{array}\right) . \mathrm{Q}(\mathrm{Cu})$ is the charge on the $\mathrm{Cu}$ atom adsorbed to a doped surface, where there are two adatoms the charges are separated by a "/"

\begin{tabular}{|c|c|c|c|c|c|c|}
\hline No. $\mathrm{Cu}$ & Ru doping site & Cu adsorption site & doped $1 \mathrm{x} 4$ & $\begin{array}{l}\mathrm{E}_{\text {bind }}[\mathrm{eV}] \\
\text { doped } 2 \times 4\end{array}$ & bare $2 \times 4$ & $\mathrm{Q}(\mathrm{Cu})$ \\
\hline $1 \mathrm{Cu}$ & RuB & $\begin{array}{l}\text { A } \\
\text { B } \\
\text { C } \\
\text { D } \\
\text { E }\end{array}$ & $\begin{array}{c}-2.88 \\
-2.02 \\
-1.88 \\
-2.56 \\
-\end{array}$ & $\begin{array}{l}-2.92 \\
-2.09 \\
-1.94 \\
-2.63 \\
-2.14\end{array}$ & $\begin{array}{c}-2.80 \\
-2.02 \\
-1.90 \\
-2.13 \\
-\end{array}$ & $\begin{array}{l}10.5 \\
10.5 \\
10.6 \\
10.4 \\
10.5\end{array}$ \\
\hline $2 \mathrm{Cu}$ & RuA & $\begin{array}{c}\text { AA"c } \\
\text { AA"a } \\
\text { AB } \\
\text { AD } \\
\text { AA"c } \\
\text { AA"a } \\
\text { AB }\end{array}$ & & $\begin{array}{l}-3.12 \\
-3.34 \\
-3.21 \\
-3.05 \\
-3.03 \\
-2.88 \\
-2.51 \\
\end{array}$ & $\begin{array}{l}-3.03 \\
-2.79 \\
-2.42 \\
-2.42 \\
-3.03 \\
-2.79 \\
-2.42 \\
\end{array}$ & $\begin{array}{l}10.5 / 10.6 \\
10.5 / 10.5 \\
10.6 / 10.5 \\
10.5 / 10.4 \\
10.5 / 10.6 \\
10.5 / 10.5 \\
10.5 / 10.5\end{array}$ \\
\hline
\end{tabular}

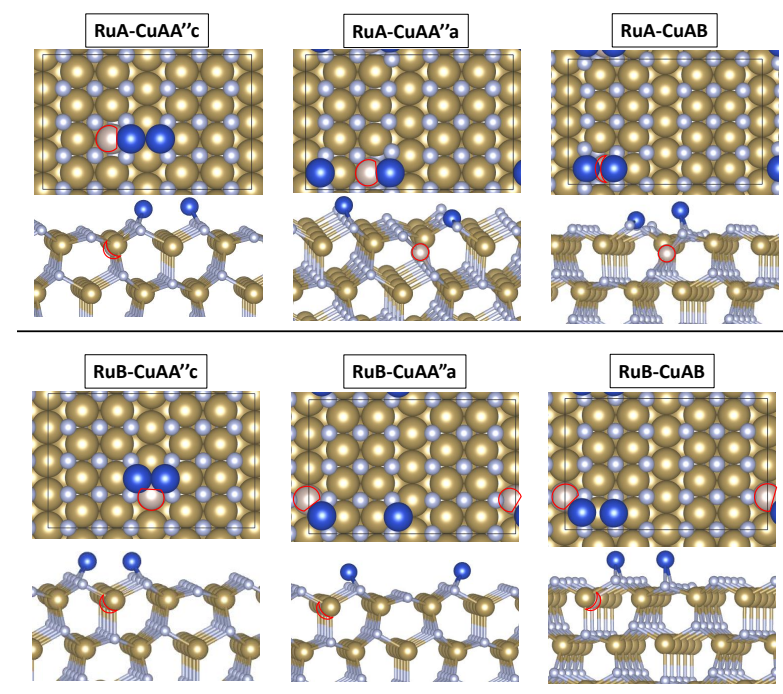

Fig. 13 The most favourable adsorption geometries of $2 \mathrm{Cu}$ atoms on RuA-doped and RuB-doped TaN(1 110$)$. The Ta, N, Ru and $\mathrm{Cu}$ atoms are shown in ochre, light blue, brown and blue, respectively. Ru atoms are highlighted with a red border.

was enhanced by an average of $-0.30 \mathrm{eV}$ when adsorbing $2 \mathrm{Cu}$ atoms on the doped surfaces when compared to the bare surface. On the bare surface, the combination of $\mathrm{AC}$ and $\mathrm{AE}$ is unstable. The combination of adsorption sites $\mathrm{A}$ and $\mathrm{E}$ is unstable on the RuA doped surface, while AC is stable. On the RuB-doped surface, $\mathrm{AC}, \mathrm{AD}$ and $\mathrm{AE}$ are all unstable configurations. As the atoms are too far apart on the surface to coordinate, the $\mathrm{Cu}$ atom placed at the E site migrates to another A site (the A"a site) on both RuA and $\mathrm{RuB}$ doped surfaces. Once the two $\mathrm{Cu}$ atoms migrate to the A site, two atoms in adjacent A sites (AA"c) is the most favourable configuration on the RuB-doped surface, with a binding energy of $-3.03 \mathrm{eV}$.

This same AA"c combination has a binding energy of $3.12 \mathrm{eV}$ on the RuA doped surface. Interestingly, this is not the most stable configuration here. Instead with a binding energy of $3.34 \mathrm{eV}$, it is more favourable for the second $\mathrm{Cu}$ atom to adsorb a distant A"a site. In addition to testing $\mathrm{Cu}$ adsorption directly on the surface, 2 $\mathrm{Cu}$ atoms were adsorbed on top of each other at an A site. When carrying out this calculation on the bare $(1 \times 4)$ surface and the doped surface, the $\mathrm{Cu}$ atoms remain stacked. On the bare $(2 \times 4)$ surface, the top $\mathrm{Cu}$ moves off and coordinates at the nearest available A site. This is possibly due to finite supercell size effects.

As for one adatom calculations, the length of bonds between $\mathrm{Cu}-\mathrm{Ru}, \mathrm{Cu}-\mathrm{Ta}, \mathrm{Cu}-\mathrm{N}, \mathrm{Ru}-\mathrm{Ta}$ and $\mathrm{Ru}-\mathrm{N}$ were measured for all adsorptions and compared to those measured for the bare surface. Results were consistent with the observations made for the one adatom calculations.

To study association using CI-NEB calculations, $2 \mathrm{Cu}$ atoms were placed at adjacent $A$ sites (AA'C) and the activation energy for one of the atoms to move to the next-nearest A site (AA'a) was computed. On the RuA surface, the activation energy needed to separate the two $\mathrm{Cu}$ atoms was $0.70 \mathrm{eV}$, while the energy to associate was $0.66 \mathrm{eV}$. On RuB, separation needed $0.60 \mathrm{eV}$ and association needed $0.72 \mathrm{eV}$. The activation energies for migration are almost symmetrical for RuA, which could be due to competing effects of $\mathrm{Cu}-\mathrm{Ru}$ interactions and $\mathrm{Cu}-\mathrm{Cu}$ interactions. On $\mathrm{RuB}$, the preference, by only $0.10 \mathrm{eV}$, is for $\mathrm{Cu}$ atoms to migrate away from each other with one atom anchored at the Ru site.

To summarize, the doping of Ru in TaN surface improves the binding strength of $\mathrm{Cu}$ and increases the activation energies for on-surface $\mathrm{Cu}$ migration as compared to bare TaN surfaces. We also find that the activation energy to migrate toward the Ru site is smaller than the activation energy to migrate away from it suggesting that the Ru dopants can act as anchor points during copper nucleation. However, the computed activation energies appear to be sensitive to the location of the doping site, therefore, additional calculations are needed where a sufficiently large surface with high percentage of doping is employed, which we plan to address in a subsequent paper.

\section{Discussion}

Cheng and co-workers ${ }^{28}$ laid down three critical conditions for the selection of an ideal liner material for copper electroplating. For the $\mathrm{Cu} / \mathrm{Ru} / \mathrm{TaN}$ system these conditions are as follows: i) adhesion of $\mathrm{Cu}$ on $\mathrm{Ru}$ must be stronger than on TaN, ii) adhesion of $\mathrm{Ru}$ on TaN must be stronger than that of $\mathrm{Cu}$ on TaN and iii) adhesion of $\mathrm{Ru}$ on TaN must be stronger than that of $\mathrm{Cu}$ on $\mathrm{Ru}$.

From our investigation that compared the interactions of one 
$\mathrm{Cu} / \mathrm{Ru}$ adatom on low-index $\varepsilon$-TaN surfaces, we found that the $\mathrm{Ru}$ adatom binds about 1.6 to 1.9 times stronger than the $\mathrm{Cu}$ adatom. On average, the $\mathrm{Cu}$ and $\mathrm{Ru}$ atoms adsorbed with a binding energy of $-2.57 \mathrm{eV}$ and $-4.95 \mathrm{eV}$, respectively. Complementing the above, the $\mathrm{Ru}$ adatom was found to have greater average activation energy for on-surface diffusion $(1.02 \mathrm{eV})$ as compared to the $\mathrm{Cu}$ adatom $(0.73 \mathrm{eV})$. Based on the above results we find that condition ii) is satisfied. The average binding energy of $\mathrm{Cu}$ on $\mathrm{Ru}(0 \quad 0$ 1) surface is $-3.16 \mathrm{eV}$, which is about $0.59 \mathrm{eV}$ stronger than $\mathrm{Cu}$ binding on the TaN surfaces and about $1.79 \mathrm{eV}$ weaker than $\mathrm{Ru}$ binding on TaN. Therefore, all the three conditions laid out by Cheng and coworkers ${ }^{28}$ are satisfied for the $\mathrm{Cu} / \mathrm{Ru} / \varepsilon$-TaN system establishing $\mathrm{Ru}$ as an ideal liner/glue material for the $\mathrm{Cu}-\varepsilon$-TaN interface as well.

From the two adatom adsorption calculations on the TaN surfaces, we found that the $\mathrm{Cu}$ and $\mathrm{Ru}$ adatoms bind with an average binding energy of $-2.85 \mathrm{eV}$ and $-5.02 \mathrm{eV}$, which are 0.28 $\mathrm{eV}$ and $0.07 \mathrm{eV}$ stronger than the one adatom cases, respectively. The additional binding energy comes from either the M$\mathrm{M}(\mathrm{M}=\mathrm{Cu}, \mathrm{Ru})$ interaction and/or the associated surface relaxations/rearrangements. From activation energy for two atom association on the TaN surfaces, we found that the $\mathrm{Cu}$ atoms would associate with lower activation energy than the $\mathrm{Ru}$ atoms except in the case of $\left(\begin{array}{lll}1 & 1 & 1\end{array}\right)$ surface where the activation energies were almost comparable.

The $\left(\begin{array}{lll}1 & 1 & 0\end{array}\right)$ surface of $\varepsilon$-TaN, with the most favourable surface energy among the low index surfaces, behaved differently from the $\left(\begin{array}{lll}1 & 1 & 1\end{array}\right)$ and (llll 100$)$ surfaces in two aspects. Firstly, the $\mathrm{Cu}$ and Ru adatoms bound comparatively strongly at the (llll) and (1 $\left.\begin{array}{lll}1 & 0\end{array}\right)$ surfaces as compared to the (1 110$)$ surface. Secondly, the $\mathrm{Cu}$ and $\mathrm{Ru}$ adatoms were oxidized on the $\left(\begin{array}{lll}1 & 1 & 0\end{array}\right)$ surface while

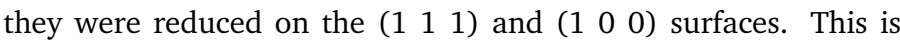
probably because of the significant difference in the $\mathrm{Ta} / \mathrm{N}$ charges and coordination geometry in the top layer of these surfaces. The Ta atoms in the first layer of the $\left(\begin{array}{lll}1 & 1 & 0\end{array}\right)$ surface were more oxidized than those on the other two surfaces which allowed subsequent oxidation of the $\mathrm{Cu} / \mathrm{Ru}$ atoms on this surface by reduction of the Ta atoms. Moreover, the largest two atom association activation energy for both $\mathrm{Ru}$ and $\mathrm{Cu}$ was found on the $\left(\begin{array}{lll}1 & 1 & 0\end{array}\right)$ surface along with significantly reduced activation energy for the reverse process (to keep them separated), therefore this surface was chosen for further analysis concerning Ru passivation and doping.

It is important to note that the on-surface diffusion of $\mathrm{Cu}$ adatoms on bare $\mathrm{Ru}\left(\begin{array}{ll}0 & 0\end{array}\right)$ surface is more favourable, along with significantly lower two atom association activation energies, than on the bare TaN surfaces. If a thick layer of $\mathrm{Ru}$ is passivated on the TaN surface, then the deposited copper atoms might diffuse and associate easily and could result in islands of $\mathrm{Cu}$ instead of a film. Therefore we first tested the copper activity on $1 \mathrm{ML}$ and 2 ML of Ru passivated TaN surfaces where the hexagonal close packing arrangement of the $\mathrm{Ru}$ atoms was already visible. The average adsorption energy of a $\mathrm{Cu}$ adatom was very similar $(-3.29 \mathrm{eV}$ $3.34 \mathrm{eV}$ ) on these surfaces and was comparable to, if not slightly larger, that on the bare $\mathrm{Ru}\left(\begin{array}{lll}0 & 0 & 1\end{array}\right)$ surface. However, the average computed activation energy for on-surface $\mathrm{Cu}$ diffusion was about $0.31 \mathrm{eV}$ on the passivated surfaces which is more favourable than

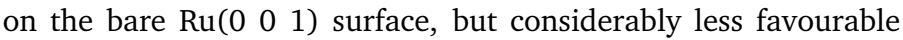
than on the bare TaN(1 110$)$ surface. This activation energy of $0.31 \mathrm{eV}$ would be easily breached under process temperatures, so we can expect very mobile $\mathrm{Cu}$ adatoms on Ru passivated TaN surfaces as well. From the $2 \mathrm{Cu}$ adsorption calculations, we saw that the copper atoms preferred to associate on these surfaces. The average energy needed to separate these associated copper atoms was found to decrease from $0.42 \mathrm{eV}$ in the $1 \mathrm{ML}$ case to $0.25 \mathrm{eV}$ in the $2 \mathrm{ML}$ case. Therefore, $1 \mathrm{ML}$ Ru passivated TaN surface is better at preventing association than the $2 \mathrm{ML}$ of Ru passivated surface which would give a thinner barrier+liner film.

The average sub-surface adsorption energies of a $\mathrm{Cu}$ adatom was $-2.78 \mathrm{eV}$ and $-2.22 \mathrm{eV}$ for the 1 and $2 \mathrm{ML}$ of Ru passivated surfaces, respectively, which are significantly more favourable than on the bare $\mathrm{Ru}\left(\begin{array}{ll}0 & 0\end{array}\right)$ surface $(-1.79 \mathrm{eV})$. This is accompanied by the fact that the average activation energy for the exchange of $\mathrm{Cu}$ and $\mathrm{Ru}$ atoms is about $0.86 \mathrm{eV}$ and $1.83 \mathrm{eV}$ for the 1 and $2 \mathrm{ML}$ of Ru passivated surfaces, which are almost twice as low as that on the bare $\mathrm{Ru}\left(\begin{array}{lll}0 & 0 & 1\end{array}\right)$ surface $(2.98 \mathrm{eV})$. So the sub-surface diffusion of $\mathrm{Cu}$ adatoms through the Ru layer via exchange process is more probable on the Ru passivated surfaces than the bare Ru. The activation energy for this exchange mechanism will probably increase when more layers of $\mathrm{Ru}$ are considered. Based on the above evidence, passivation of TaN surfaces with Ru may not be the best solution there is to avoid $\mathrm{Cu}$ association and enhance $\mathrm{Cu}$ binding. As an alternative, we looked at Ru doped TaN surfaces which would also reduce the overall layer thickness.

We considered two Ru doped TaN ( $\left.\begin{array}{lll}1 & 1 & 0\end{array}\right)$ surfaces where a S or F type surface Ta atom is replaced by a Ru atom (RuA or RuB). The RuB doped surface is energetically more favourable than the RuA doped surface and the RuA atom is more oxidized than the $\mathrm{RuB}$. The Ru doping does not introduce significant changes in the surface lattice as well as surface charge distribution. Differences, if any, are small and localized to the doping site. Overall the $\mathrm{Cu}$ binding energy is more favourable when $\mathrm{Ru}$ is present in the TaN (1 110 ) surface, more so when the $\mathrm{Cu}$ atom is bound to the doped $\mathrm{Ru}$. The $\mathrm{Cu}$ binding energies and the surface geometry did not change with a larger surface supercell, which also suggested that the effect of Ru doping is local. The average $1 \mathrm{Cu}$ binding energy on the Ru doped surface is about $-2.46 \mathrm{eV}$, which is $0.86 \mathrm{eV}$ weaker than that on the Ru passivated surfaces. However, the adsorption energies were significantly decreased to an average of 2.88 when $2 \mathrm{Cu}$ atoms are adsorbed due to the increased $\mathrm{Cu}-\mathrm{Ru}$ and $\mathrm{Cu}$-Cu binding. On the other hand, the on-surface diffusion of $\mathrm{Cu}$ atoms and two atom association are considerably hindered on the Ru doped surfaces as compared to the Ru passivated surfaces. In fact, the two atom association activation energies on the doped surfaces are comparable to that of bare TaN surface. Further, the sub surface adsorption and diffusion of the $\mathrm{Cu}$ atoms are also comparatively less favourable on the Ru doped surfaces as compared to the Ru passivated surfaces. We also showed that the migration of $\mathrm{Cu}$ towards the doped $\mathrm{Ru}$ is more favourable than the migration away from it. This suggested clearly that the Ru binding sites can be anchor points for $\mathrm{Cu}$ nucleation during the initial stages of the deposition process. Therefore, a higher percentage of Ru doping would ensure that the $\mathrm{Cu}$ atoms do not associate on the surface. 
In any case additional calculations on much larger surface models are needed to confirm the above, which will be addressed in our next paper.

Compared to the $\mathrm{Ru}$ passivated surfaces where the $\mathrm{Cu}$ atoms diffuse and associate easily despite the more favourable binding of $\mathrm{Cu}$, the $\mathrm{Ru}$ doped surfaces provide smaller activation energies toward diffusion and association of the adosorbed $\mathrm{Cu}$ atoms. Moreover, the $\mathrm{Cu}$ binding energies on the $\mathrm{Ru}$ doped surfaces are more favourable as compared to bare TaN surfaces and we expect further improvements as the percentage of $\mathrm{Ru}$ doping is increased. Therefore, we find that the Ru doped surfaces exhibit a great potential as a combined barrier + liner material, as the addition of $\mathrm{Ru}$ modifies the TaN surface to give increased binding and provide anchoring sites for the $\mathrm{Cu}$ nucleation, which should promote wetting of $\mathrm{Cu}$ while retaining the barrier properties of TaN.

\section{Conclusions}

We have investigated the viability of $\mathrm{Ru}$ passivated and $\mathrm{Ru}$ doped $\varepsilon$-TaN surfaces as an effective diffusion barrier+liner material for copper interconnect technology. We started by studying the activity of $\mathrm{Cu}$ and $\mathrm{Ru}$ adatoms on bare $\varepsilon$-TaN surfaces and found that $\mathrm{Ru}$ binds significantly stronger and diffuses slower than $\mathrm{Cu}$. $\mathrm{Cu}$ was found to bind at the Ru(0 01 1) surface with roughly the same average binding energy as at the TaN surfaces, however, $\mathrm{Cu}$ diffused faster on the Ru surface. On-surface association and sub-surface adsorption of $\mathrm{Cu}$ atoms were relatively more favourable at the

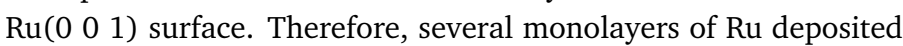
on TaN can not be considered as the most effective barrier+liner material.

TaN ( $\left.\begin{array}{lll}1 & 1 & 0\end{array}\right)$ surface was chosen for the Ru passivation and doping studies since both $\mathrm{Ru}$ and $\mathrm{Cu}$ adatoms did not prefer to associate on it as compared to ( $\left(\begin{array}{lll}1 & 1 & 1\end{array}\right)$ and (llll 100$)$ surfaces. On the $\mathrm{Ru}$ passivated ( $\left.\begin{array}{lll}1 & 1 & 0\end{array}\right)$ surfaces, $\mathrm{Cu}$ atoms bind more strongly than on the bare TaN and Ru surfaces. However, the adsorbed $\mathrm{Cu}$ atoms diffused faster than on the bare TaN surfaces and preferred to associate. Although 1 or $2 \mathrm{ML}$ of Ru passivation on TaN was a better alternative to several layers of $\mathrm{Ru}$ on TaN, it still lacks the association behaviour that we are expecting in the combined barrier+liner material. Finally, we looked at Ru doped TaN surface as a viable alternative. On the $\mathrm{Ru}$ doped surfaces, even though the $\mathrm{Cu}$ adatoms showed decreased $\mathrm{Cu}$ binding as compared to the $\mathrm{Ru}$ passivated surfaces, they offered significantly larger activation energies for the on-surface and sub-surface diffusion as well as association of $\mathrm{Cu}$ atoms. We also expect the $\mathrm{Cu}$ binding to improve at higher percentage of Ru doping. Therefore we find the $\mathrm{Ru}$ doped TaN surfaces to be a promising combined barrier+liner material which incorporates both the liner properties of $\mathrm{Ru}$ and barrier properties of TaN.

\section{Conflicts of interest}

There are no conflicts to declare.

\section{Acknowledgements}

The authors would like to thank SFI-NSFC Partnership NITRALD (17/NSFC/2975) for project funding and the Tyndall computing centre for the computer time.

\section{Notes and references}

1 P. S. Peercy, Nature, 2000, 406, 1023-1026.

2 M. T. Bohr, Int. El. Devices Meet., 1995, 241-244.

3 K. N. Tu, J. Appl. Phys., 2003, 94, 5451-5473.

4 B. Li, C. Christiansen, D. Badami and C.-C. Yang, Microelectron. Reliab., 2014, 54, 712-724.

5 S.-Q. Wang, MRS Bull., 1994, 19, 30-40.

6 D. C. Edelstein, Int. El. Devices Meet., 2017, 14.1.1-14.1.4.

7 Z. Wang, T. Ida, H. Sakaue, S. Shingubara and T. Takahagi, Electrochem. Solid St., 2003, 6, C38-C41.

8 B. Pesic, ECS Transactions, 2007, 2, 243-256.

9 H. Wong, N. M. Shukor and N. Amin, Microelectron. J., 2007, 38, 777-782.

10 A. E. Kaloyeros and E. Eisenbraun, Annu. Rev. Mater. Sci., 2000, 30, 363-385.

11 M. Uekubo, T. Oku, K. Nii, M. Murakami, K. Takahiro, S. Yamaguchi, T. Nakano and T. Ohta, Thin Solid Films, 1996, 286, 170-175.

12 K. Holloway and P. M. Fryer, Appl. Phys. Lett., 1990, 57, 17361738.

13 H. Kim, Y. Naito, T. Koseki, T. Ohba, T. Ohta, Y. Kojima, H. Sato and Y. Shimogaki, Jpn. J. Appl. Phys., 2006, 45, 2497-2501.

14 O. Chyan, T. N. Arunagiri and T. Ponnuswamy, J. Electrochem. Soc., 2005, 150, C347-C350.

15 T. N. Arunagiri, Y. Zhang, O. Chyan, M. El-Bouanani, M. J. Kim, K. H. Chen, C. T. Wu and L. C. Chen, Appl. Phys. Lett., 2005, 86, 083104-1-083104-3.

16 N. Torazawa, S. Hirao, S. Kanayama, H. Korogi and S. Matsumoto, J. Electrochem. Soc., 2016, 163, E173-E178.

17 K. Min, K. Chun and K. Kim, J. Vac. Sci. Technol. B, 1996, 14, 3263-3269.

18 Y. Zhao and G. Lu, Phys. Rev. B, 2009, 79, 214104-1-214104-9.

19 K.-C. Park and K.-B. Kim, J. Electrochem. Soc., 1995, 142, 3109-3115.

20 K. S. Novoselov, D. Jiang, F. Schedin, T. J. Booth, V. V. Khotkevich, S. V. Morozov and A. K. Geim, P. Natl. Acad. Sci., 2005, 102, 10451-10453.

21 W. Choi, N. Choudhary, G. H. Han, J. Park, D. Akinwande and Y. H. Lee, Mater. Today, 2017, 20, 116-130.

22 C. Lo, K. Zhang, J. A. Robinson and Z. Chen, 2018 Int. Symp. VLSI Technol., Sys. Appl. (VLSI-TSA), 2018, 1-2. 
23 D. V. Greenslit and E. Eisenbraun, ECS Transactions, 2011, 35, 17-24.

24 S. M. George, Chem. Rev., 2010, 110, 111-131.

25 K. J. Kanarik, T. Lill, E. A. Hudson, S. Sriraman, S. Tan, J. Marks, V. Vahedi and R. A. Gottscho, J. Vac. Sci. Technol. A, 2015, 33, 020802-1-020802-14.

26 Z. Wu, R. Li, X. Xie, W. Suen, J. Tseng, N. Bekiaris, R. Vinnakota, K. Kashefizadeh and M. Naik, 2018 Int. Interconnect Technology Conf. (IITC), 2018, 149-151.

27 M. Stavrev, D. Fischer, F. Praessler, C. Wenzel and K. Drescher, J. Vac. Sci. Technol. A, 1999, 17, 993-1001.

28 B. Han, J. Wu, C. Zhou, B. Chen, R. Gordon, X. Lei, D. A. Roberts and H. Cheng, Angew. Chem. Int. Edit., 2010, 49, 148152.

29 S.-F. Ding, H.-S. Lu, F. Chen, Y.-L. Jiang, G.-P. Ru, D. W. Zhang and X.-P. Qu, Jpn. J. Appl. Phys., 2011, 50, 105701-1-1057015 .

30 K. Frisk, J. Alloy. Compd., 1998, 278, 216-226.

31 A. Christensen and B. Lebech, Acta Crystallogr. B, 1978, 34, 261-263.

32 N. C. Hernandez, A. Marquez, J. F. Sanz, J. R. B. Gomes and F. Illas, J. Phys. Chem. B, 2004, 108, $15671-15678$.

33 A. D. Vitto, G. Pacchioni, F. O. Delbecq and P. Sautet, J. Phys. Chem. B, 2005, 109, 8040-8048.

34 L. Giordano, M. Baistrocchi and G. Pacchioni, Phys. Rev. B, 2005, 72, 115403-1-115403-12-.

35 M. Nolan, S. D. Elliott, J. S. Mulley, R. A. Bennett, M. Basham and P. Mulheran, Phys. Rev. B, 2008, 77, 235424-1-235424-11.

36 M. Nolan, J. Chem. Phys., 2012, 136, 134703-1-134703-9.

37 W. Q. Li, S. G. Srinivasan, D. R. Salahub and T. Heine, Phys. Chem. Chem. Phys., 2016, 18, 11139-11149.

38 H. Pinto, V. Haapasilta, M. Lokhandwala, S. Oberg and A. S. Foster, J. Phys.: Condens. Matter, 2017, 29, 135001-1-1350015.

39 N. J. O'Connor, A. S. M. Jonayat, M. J. Janik and T. P. Senftle, Nat. Catal., 2018, 1, 531-539.

40 I. A. Pasti, B. Johansson and N. V. Skorodumova, Phys. Chem. Chem. Phys., 2018, 20, 6337-6346.

41 Y. Chen, S. Ji, C. Chen, Q. Peng, D. Wang and Y. Li, Joule, 2018, 2, 1242-1264.

42 N. Dimakis, I. Salas, L. Gonzalez, O. Vadodaria, K. Ruiz and M. I. Bhatti, Molecules, 2019, 24, 754-1-754-28.

43 G. Kresse and J. Furthmuller, Phys. Rev. B, 1996, 54, 1116911186.
44 P. Blochl, Phys. Rev. B, 1994, 50, 17953-17979.

45 G. Kresse and D. Joubert, Phys. Rev. B, 1999, 59, 1758-1775.

46 J. P. Perdew, K. Burke and M. Ernzerhof, Phys. Rev. Lett., 1996, 77, 3865-3868.

47 G. Henkelman and H. Jonsson, J. Chem. Phys., 2000, 113, 9978-9985.

48 G. Henkelman, B. P. Uberuaga and H. Jonsson, J. Chem. Phys., 2000, 113, 9901-9904.

49 K. Persson, Materials Data on TaN by Materials Project, 2015, URL: https://materialsproject.org/materials/mp-1279/, accessed on $21 / 11 / 2018$.

50 E. Sanville, S. D. Kenny, R. Smith and G. Henkelman, J. Comput. Chem., 2007, 28, 899-908.

51 G. Henkelman, A. Arnaldsson and H. Jónsson, Comp. Mater. Sci., 2006, 36, 354-360.

52 K. Persson, Materials Data on Ta by Materials Project, 2016, URL: https://materialsproject.org/materials/mp-50/, accessed on $21 / 11 / 2018$.

53 A. Hjorth Larsen, J. J. Mortensen, J. Blomqvist, I. E. Castelli, R. Christensen, M. Dulak, J. Friis, M. N. Groves, B. Hammer, C. Hargus, E. D. Hermes, P. C. Jennings, P. B. Jensen, J. Kermode, J. R. Kitchin, E. L. Kolsbjerg, J. Kubal, K. Kaasbjerg, S. Lysgaard, J. B. Maronsson, T. Maxson, T. Olsen, L. Pastewka, A. Peterson, C. Rostgaard, J. Schiotz, O. Schutt, M. Strange, K. S. Thygesen, T. Vegge, L. Vilhelmsen, M. Walter, Z. Zeng and K. W. Jacobsen, J. Phys-condens. Mat., 2017, 29, 2730021-273002-30.

54 K. Persson, Materials Data on Ru by Materials Project, 2016, URL: https://materialsproject.org/materials/mp-33/, accessed on $21 / 11 / 2018$.

55 J. W. Arblaster, Platin. Met. Rev., 2013, 57, 127-136.

56 E. Kaxiras, Atomic and Electronic Structure of Solids, Cambridge University Press, 2003.

57 S.-F. Ding, S.-R. Deng, H.-S. Lu, Y.-L. Jiang, G.-P. Ru, D. W. Zhang and X.-P. Qu, J. Appl. Phys., 2010, 107, 103534-1103534-7. 